\title{
5. Estrutura atual e estimativas futuras da força de trabalho em medicina, enfermagem e odontologia no Brasil - 2000 a 2030
}

\author{
Sabado Nicolau Girardi \\ Lucas Wan Der Maas \\ Cristiana Leite Carvalho \\ Celia Regina Pierantoni
}

\section{SciELO Books / SciELO Livros / SciELO Libros}

GIRARGI, S.N., WAN DER MAAS, L., CARVALHO, C.L., and PIERANTONI, C.R. Estrutura atual e estimativas futuras da força de trabalho em medicina, enfermagem e odontologia no Brasil - 2000 a 2030. In: NORONHA, J.C., LIMA, L.D., CHORNY, A.H., DAL POZ, M.R., and GADELHA, P., eds. Brasil Saúde Amanhã: dimensões para o planejamento da atenção à saúde [online]. Rio de Janeiro: Editora FIOCRUZ, 2017, pp. 189-212. ISBN: 978-65-5708-090-0.

https://doi.org/10.7476/9786557080900.0007.

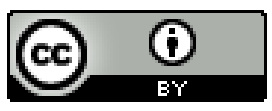

All the contents of this work, except where otherwise noted, is licensed under a Creative Commons Attribution $\underline{4.0 \text { International license. }}$

Todo o conteúdo deste trabalho, exceto quando houver ressalva, é publicado sob a licença Creative Commons Atribição 4.0.

Todo el contenido de esta obra, excepto donde se indique lo contrario, está bajo licencia de la licencia $\underline{\text { Creative }}$ Commons Reconocimento 4.0. 


\title{
ESTRUTURA ATUAL E ESTIMATIVAS FUTURAS DA FORÇA DE TRABALHO EM MEDICINA, ENFERMAGEM E ODONTOLOGIA NO BRASIL - 2000 A 2030
}

\author{
Sabado Nicolau Girardi \\ Lucas Wan Der Maas \\ Cristiana Leite Carvalho \\ Celia Regina Pierantoni
}

Nas duas últimas décadas no Brasil e, sobretudo, na segunda metade da primeira década de 2000, assistiu-se a um importante crescimento da economia e da força de trabalho nacional. Após duas décadas de crise nos mercados de trabalho, informalização da economia e precarização das relações de trabalho, verifica-se a partir dos anos 2000 uma importante recuperação do emprego formal e dos salários. Nesse contexto, as atividades da saúde ampliaram os números da sua força de trabalho em proporções muito superiores ao total da economia. Entre 2000 e 2010, a força de trabalho ocupada em atividades de saúde cresceu a 5,5\% ao ano diante do incremento de 2,8\% ao ano do total de outras atividades. Em termos absolutos, o volume da ocupação no macrossetor quase dobrou, de 3,5 para 6,0 milhões de pessoas, passando de 5,4\% para mais de 7\% do total da economia (Tabela 1).

De fato, o mercado de trabalho em saúde no Brasil se desenvolveu nesse período em um contexto demográfico, econômico, social, político e cultural de crescentes demandas por serviços de saúde. Demograficamente, podem-se destacar o crescimento e o envelhecimento da população no país como explicativos dessa demanda (Carvalho \& Garcia, 2003). Do ponto de vista socioeconômico, a já citada recuperação do mercado de trabalho e a ascensão social de parte significativa da população estimularam o consumo dos planos de assistência médica e geraram fortes pressões para produção de bens, serviços e tecnologias de saúde mais diversos e de qualidade (Dal Poz, Pierantoni \& Girardi, 2012). Politicamente, a própria implantação e consolidação do Sistema Único de Saúde (SUS) e o avanço das políticas públicas da área, a exemplo da Estratégia Saúde da Família (ESF) - principal responsável por descentralizar o acesso à assistência básica em saúde -, resultaram na demanda substancial por recursos humanos (Girardi et al., 2010).

Entre as profissões e ocupações da saúde, o aumento da força de trabalho ocupada, de 8,2\%, foi ainda maior em relação ao setor Saúde como um todo. Em 2010, a força de trabalho ocupada no macrossetor Saúde ${ }^{1}$ correspondia a 7\% do total de ocupados no Brasil (ante 5,4\% em 2000), tota-

\footnotetext{
${ }^{1}$ O conceito de macrossetor Saúde guarda similaridade ao de complexo produtivo da saúde, englobando além dos serviços de saúde propriamente ditos, as atividades de produção e distribuição de fármacos, vacinas e medicamentos para uso humano; a produção de insumos e equipamentos para o setor; as atividades de ensino, pesquisa e desenvolvimento; as atividades de financiamento e planos de saúde; as atividades de saneamento e a gestão governamental dos serviços de saúde. Para maiores detalhes sobre o conceito e estimativas ver Zaeyen e colaboradores (1995).
} 
lizando 6,049 milhões de pessoas (Tabela 1). Desses, 4,493 milhões estavam ocupados em serviços de saúde propriamente ditos - o núcleo do setor - sendo 2,451 milhões em ocupações de saúde (ou seja, médicos, enfermeiros, cirurgiões-dentistas, farmacêuticos, técnicos de enfermagem, técnicos em radiologia, agentes comunitários de saúde etc.) e 1,257 milhão em ocupações não saúde (funções administrativas, serviços gerais, limpeza e conservação etc.). Além disso, 784 mil pessoas estavam em ocupações de saúde nas atividades industriais, de ensino, comércio, entre outras ligadas diretamente à área.

Os médicos e cirurgiões-dentistas experimentaram crescimento inferior à média do total de ocupações de saúde e bem próximo do observado para o total da economia, respectivamente, 3\% e $2,9 \%$ ao ano (Tabela 1). Já entre os enfermeiros o crescimento foi explosivo, de 14,9\%. Em todos os casos, o incremento da força de trabalho em saúde acompanhou a enorme expansão do ensino superior verificada no período.

Tabela 1 - Distribuição do número de ocupados em saúde* discriminados por ocupações de saúde e não saúde. Brasil - 2000 e 2010

\begin{tabular}{|c|c|c|c|c|c|}
\hline & \multicolumn{2}{|c|}{2000} & \multicolumn{2}{|c|}{2010} & \multirow{2}{*}{$\begin{array}{l}\text { Incremento } \\
\text { geométrico }\end{array}$} \\
\hline & $\mathrm{N}$ & $\%$ & $\mathrm{~N}$ & $\%$ & \\
\hline Pop. ocupada no macrossetor Saúde & 3.536 .862 & 100 & 6.049 .479 & 100 & 5,5 \\
\hline Ocupações da Saúde & 1.476 .226 & 41,7 & 3.236 .060 & 53,5 & 8,2 \\
\hline Médicos** & 243.830 & 6,9 & 328.006 & 5,4 & 3,0 \\
\hline Enfermeiros** & 76.961 & 2,2 & 308.429 & 5,1 & 14,9 \\
\hline Cirurgiões-dentistas*** & 161.896 & 4,6 & 214.909 & 3,6 & 2,9 \\
\hline Ocupações Não Saúde & 2.060 .637 & 58,3 & 2.813 .419 & 46,5 & 3,2 \\
\hline Núcleo do setor & 2.443 .632 & 69,1 & 3.708 .704 & 61,3 & 4,3 \\
\hline Pop. ocupada no total da economia & \multicolumn{2}{|c|}{65.629 .892} & \multicolumn{2}{|c|}{86.353 .839} & 2,8 \\
\hline $\begin{array}{l}\% \text { do macrossetor no total da } \\
\text { economia }\end{array}$ & \multicolumn{2}{|c|}{5,4} & \multicolumn{2}{|c|}{7,0} & \\
\hline
\end{tabular}

* No trabalho principal da semana de referência.

**Ocupados na própria profissão ou em outra função.

Fonte: elaboração própria, com base em dados do IBGE (2002, 2012). 


\section{Estrutura Atual da Força de Trabalho}

\section{Perfil ocupacional}

No censo demográfico do Instituto Brasileiro de Geografia e Estatística (IBGE) de 2010, informava-se a existência de 355.583 médicos residentes no país, valor próximo ao de profissionais com registro ativo no Conselho Federal de Medicina no mesmo ano, que era de 364.757 (Tabela 2). Dos recenseados, 328.006 médicos ( $92 \%$ do total) estavam economicamente ativos na semana de referência do inquérito, e 286.399 (80,5\%) exerciam a função de médicos como trabalho principal da semana de referência, 39.734 (11,2\%) se ocupavam em outras funções e 1.873 (0,5\%) estavam desocupados. Como o IBGE coleta informações apenas sobre o trabalho principal, supõe-se que parte dos ocupados em outras funções também exercia a medicina nos trabalhos secundários, totalizando algo em torno de 300 mil pessoas. À mesma época, 190.503 detinham vínculos formais de emprego, como celetistas, estatutários e demais vínculos assalariados regulares (Brasil, 2011). Considerando que os médicos se vinculam ao mercado de trabalho e a serviços de saúde de distintas formas, como autônomos - tradicionais ou em rede -, cooperados, pessoas jurídicas, além de se empregarem em atividades de outras áreas (ensino, administração etc.), esse volume de emprego corrobora a tese da existência de plena ocupação dos médicos na economia brasileira.

O número total de enfermeiros contabilizados no censo foi de 355.383, número próximo ao registrado no Conselho Federal de Enfermagem (Cofen, 2013), de 346.968 em 2013. Acredita-se que essa diferença, no entanto, não representa inflexão no número de registrados, mas um hiato entre formados na profissão e portadores de registro. Ao contrário do que foi observado entre os médicos, menos da metade dos enfermeiros $(46,7 \%)$ tinha como trabalho principal as atividades típicas da profissão, ainda que 308.429 (86,8\%) estivessem economicamente ativos. Ressalta-se que parte dos enfermeiros ocupados em outras funções estava na própria área de enfermagem, como técnicos e auxiliares de enfermagem e "cuidadores pessoais" (cerca de 50 mil pessoas). Ao mesmo tempo, por meio dos números da Relação Anual de Informações Sociais (Rais) constatava-se que 168.662 mil enfermeiros detinham empregos regulares na economia formal, o que sugere uma forte formalização da categoria, quando ocupada na profissão.

Para cirurgiões-dentistas o número encontrado no censo de 2010 foi de 241.622 profissionais, sendo 214.909 (88,9\%) ativos, 187.172 (77,5\%) ocupados na profissão e 2.122 (0,9\%) desocupados, proporções muito próximas às encontradas entre médicos. Os registros de ativos em 2013, segundo o Conselho Federal de Odontologia (CFO, 2013), totalizavam 251.587 pessoas. Quanto aos empregados no mercado formal, verifica-se aqui importante diferença entre os cirurgiões-dentistas e outras profissões em análise. Trata-se de uma força de trabalho com baixa proporção de vínculos empregatícios formais em relação aos ocupados na economia (56.310 profissionais com emprego formal em 2010 ou 23\% do total). Em parte, isso pode ser explicado pela predominância das formas de trabalho autônomas, tanto a de autônomos tradicionais estabelecidos em consultórios privados quanto empregados informalmente em clínicas onde predominam as relações de pagamento por porcentagem. 
Tabela 2 - Número de médicos, enfermeiros e cirurgiões-dentistas residentes no país em 2010, por condição de atividade, registrados nos conselhos profissionais em 2013 e ocupados na economia formal em 2010

\begin{tabular}{|c|r|r|r|}
\hline \multicolumn{1}{|c|}{ Indicador } & \multicolumn{1}{|c|}{ Médicos } & Enfermeiros & Cirurgiões-dentistas \\
\hline $\begin{array}{l}\text { 1. Profissionais residentes no país } \\
\text { 1.1. Economicamente ativos }\end{array}$ & 355.583 & 355.383 & 241.622 \\
\hline $\begin{array}{l}\text { Ocupados na profissão } \\
\text { Ocupados em outra função }\end{array}$ & $286.399(80,5 \%)$ & $165.797(46,7 \%)$ & $187.172(77,5 \%)$ \\
\hline $\begin{array}{l}\text { Desocupados } \\
\text { 1.2. Não economicamente ativos }\end{array}$ & $1.873(0,5 \%)$ & $19.011(5,4 \%)$ & $2.122(0,9 \%)$ \\
\hline $\begin{array}{l}\text { 2. Profissionais em atividade em } \\
\text { 2013(CFM, Cofen e CFO) }\end{array}$ & $27.577(7,8 \%)$ & $46.955(13,2 \%)$ & $26.713(11,1 \%)$ \\
\hline $\begin{array}{l}\text { 3. Número de profissionais empregados } \\
\text { na economia formal (Rais 2010) }\end{array}$ & 373.991 & $123.621(34,8 \%)$ & $25.615(10,6 \%)$ \\
\hline
\end{tabular}

Fonte: elaboração própria, com base em dados do IBGE $(2002,2012)$.

\section{Composição demográfica}

Quanto à composição por sexo e idade das populações em questão, as pirâmides etárias a seguir (Gráficos 1 a 3) permitem identificar, para a população economicamente ativa, a transição ocorrida entre os anos 2000 e 2010 no que diz respeito a essa composição. Nos três casos, observou-se rejuvenescimento da força de trabalho, isto é, aumento de pessoas na base da pirâmide. Tal crescimento se explica basicamente por abertura de vagas no ensino superior ao longo das duas últimas décadas. Identificou-se ainda que esse crescimento ocorreu principalmente entre mulheres.

No topo das pirâmides de médicos e cirurgiões-dentistas, nota-se um envelhecimento, principalmente entre os homens, o que reflete a característica de uma força de trabalho na qual a aposentadoria em um vínculo de emprego formal, seja do tipo estatutário ou celetista, não implica necessariamente abandono da atividade laboral. Essa continuidade do exercício laboral se explica fundamentalmente pela importância da prática autônoma convencional e das formas de trabalho autônomas consorciadas em cooperativas e do trabalho organizado na forma de pessoa jurídica. As pirâmides de médicos e cirurgiões-dentistas, no entanto, apresentam uma diferença no centro da pirâmide, já que nas faixas etárias entre 40 e 60 anos o volume de médicos é mais estreito em relação à base, o que é explicado por uma oferta de egressos do ensino superior mais restritiva entre as décadas de 1970 e 1980, comparativamente às décadas posteriores. No caso específico da odontologia, o crescimento do número vagas e egressos no ensino superior tem se mostrado estável, o que explicaria o formato quase triangular da pirâmide.

O envelhecimento e a feminização observados durante a década de 2000, em medicina e odontologia, indicam pelo menos duas tendências para os próximos anos. Em primeiro lugar, o volume de saídas da força de trabalho, por morte ou aposentadoria definitiva, será maior do que no passado, o que deverá ocorrer não só em termos absolutos, mas também relativos. Note que a proporção de 
médicos não economicamente ativos em relação ao total, em 2010, era de 7,8\% (Tabela 2), mesmo com o aumento no número de médicos com mais de 60 anos desde o início da década, o que provavelmente não será sustentado. Em segundo lugar, o crescimento da participação feminina expõe uma redução da carga horária média de dedicação ao trabalho, bem como do tempo médio de permanência no mercado ao longo da vida. Esses dois fatores certamente impulsionarão o crescimento da demanda por novos profissionais nos próximos anos.

A enfermagem apresentou comportamento diferente nessa transição entre os anos censitários. O que se deve destacar, de fato, é o substancial incremento do número de pessoas (alargamento da base da pirâmide) e a permanência de uma maioria feminina. Além disso, ao contrário do que se demonstrou para as outras duas profissões, o topo da pirâmide não se alterou, do ponto de vista da composição, já que, nesse caso, a saída do mercado de trabalho ocorre no início da terceira idade, sobretudo como resultado da aposentadoria e da predominância das relações de trabalho heterônomas - tanto entre os ocupados na profissão quanto em outras funções. Como destacado, a enfermagem é uma categoria altamente formalizada e, portanto, dependente de uma trajetória típica de atuação no mercado de trabalho ao longo da vida. As altas proporções de mulheres sugerem ainda que as saídas do mercado ocorrem em menor tempo se comparadas a profissões com maior proporção de homens. Nenhuma evidência aponta que tais tendências se alterarão em longo prazo e que a demanda por enfermeiros está mais condicionada à capacidade de acomodação do mercado como se verá adiante, afinal mais da metade dos graduados não exerce a profissão de enfermeiro.

Gráfico 1 - Composição etária e de sexo da população economicamente ativa de médicos. Brasil 2000 e 2010

2000

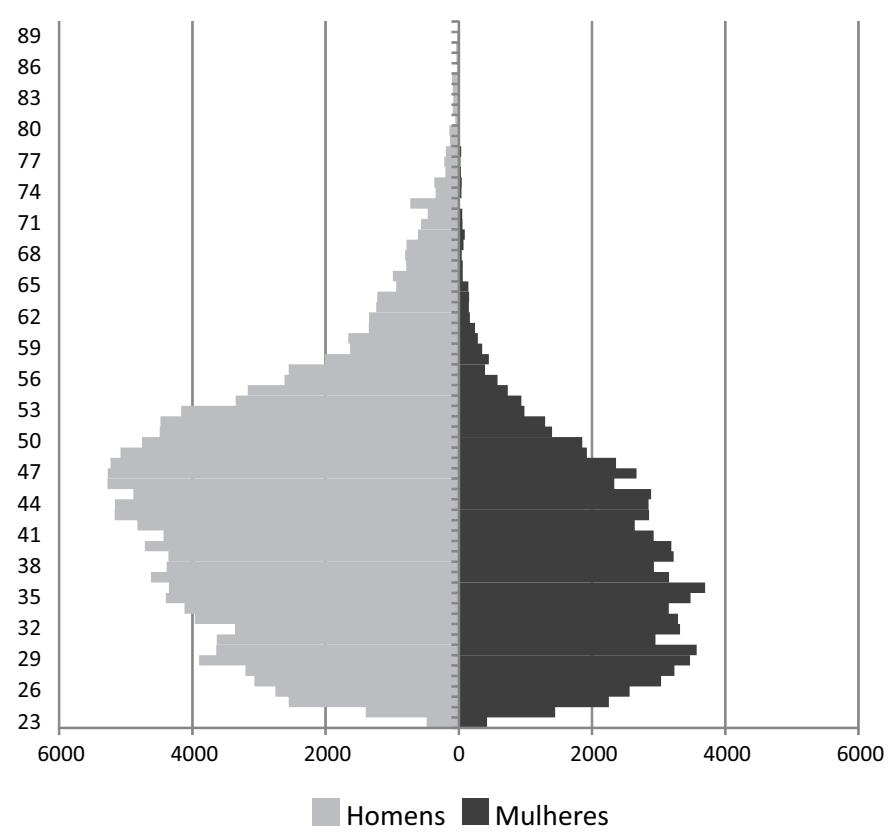

2010

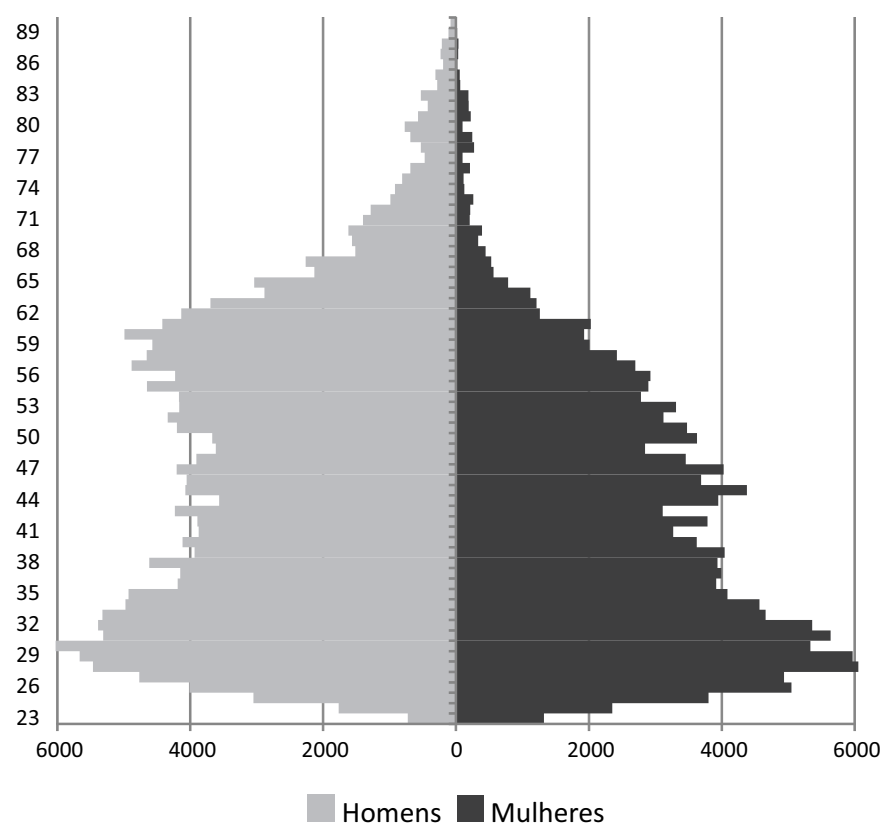

Fonte: elaboração própria, com base em dados do IBGE $(2002,2012)$. 
Gráfico 2 - Composição etária e de sexo da população economicamente ativa de enfermeiros. Brasil -2000 e 2010
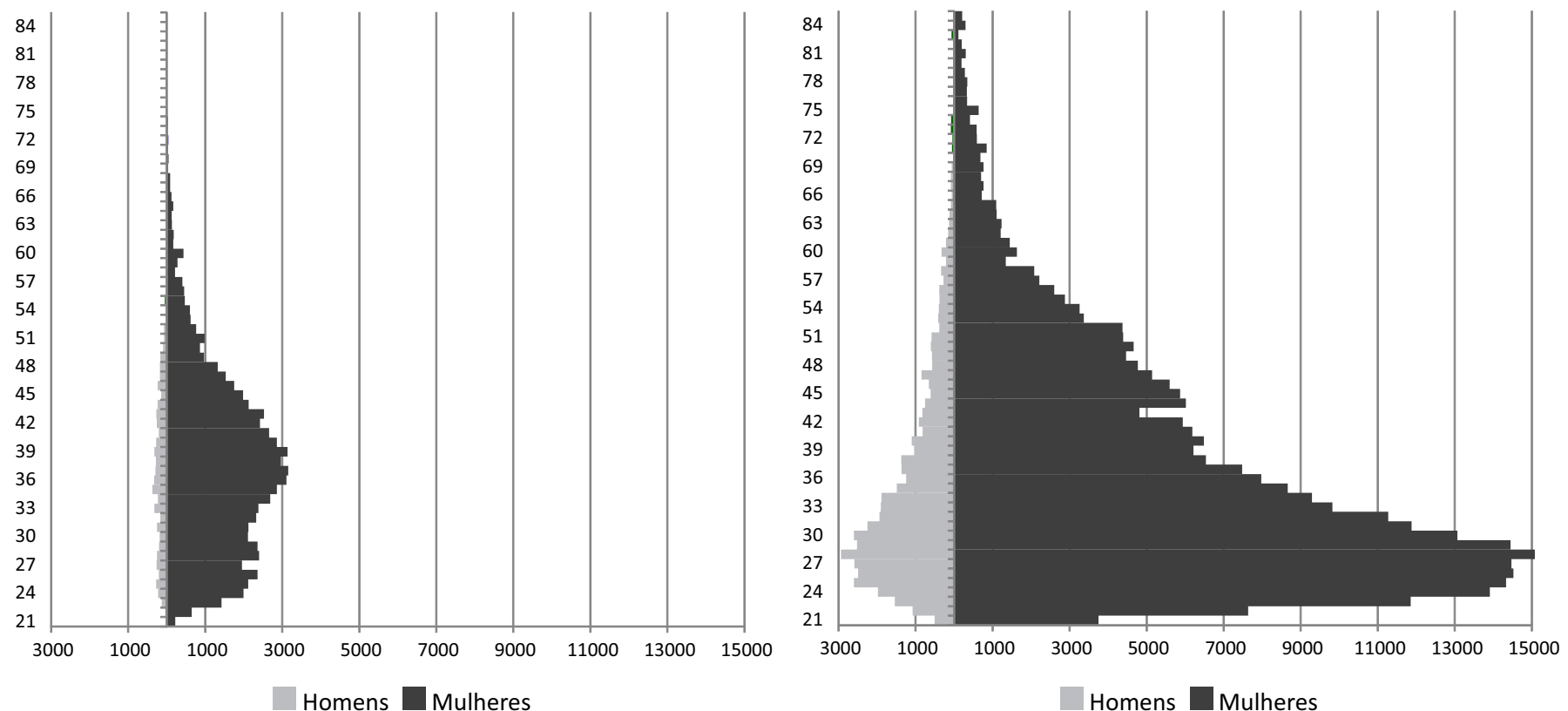

Fonte: elaboração própria, com base em dados do IBGE (2002, 2012).

Gráfico 3 - Composição etária e de sexo da população economicamente ativa de cirurgiões-dentistas. Brasil - 2000 e 2010

2000

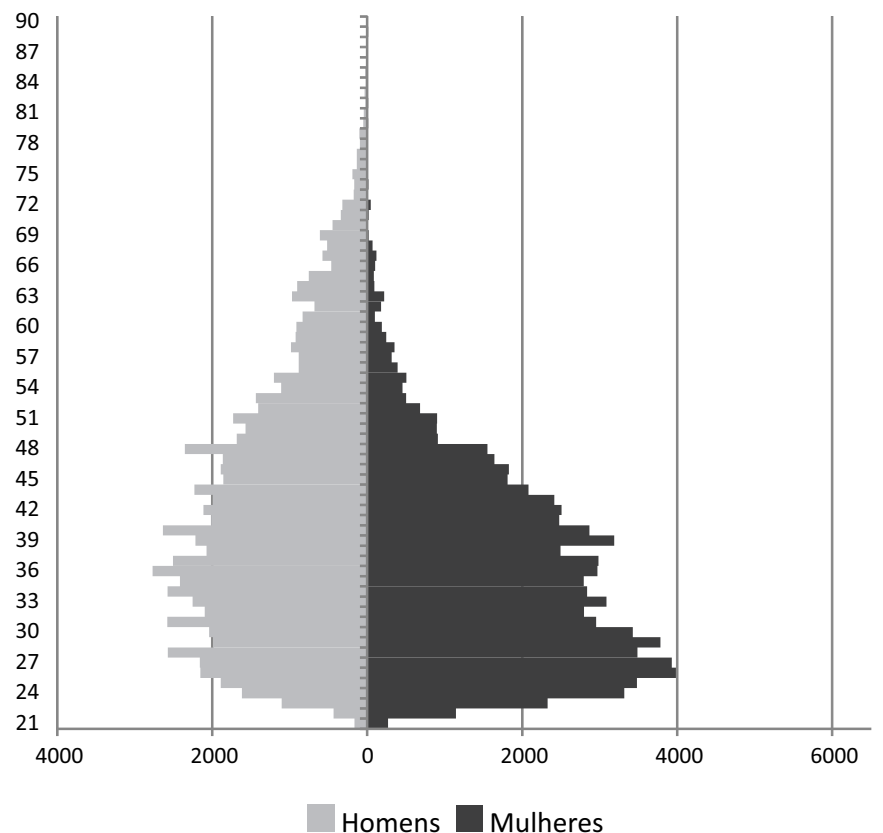

2010

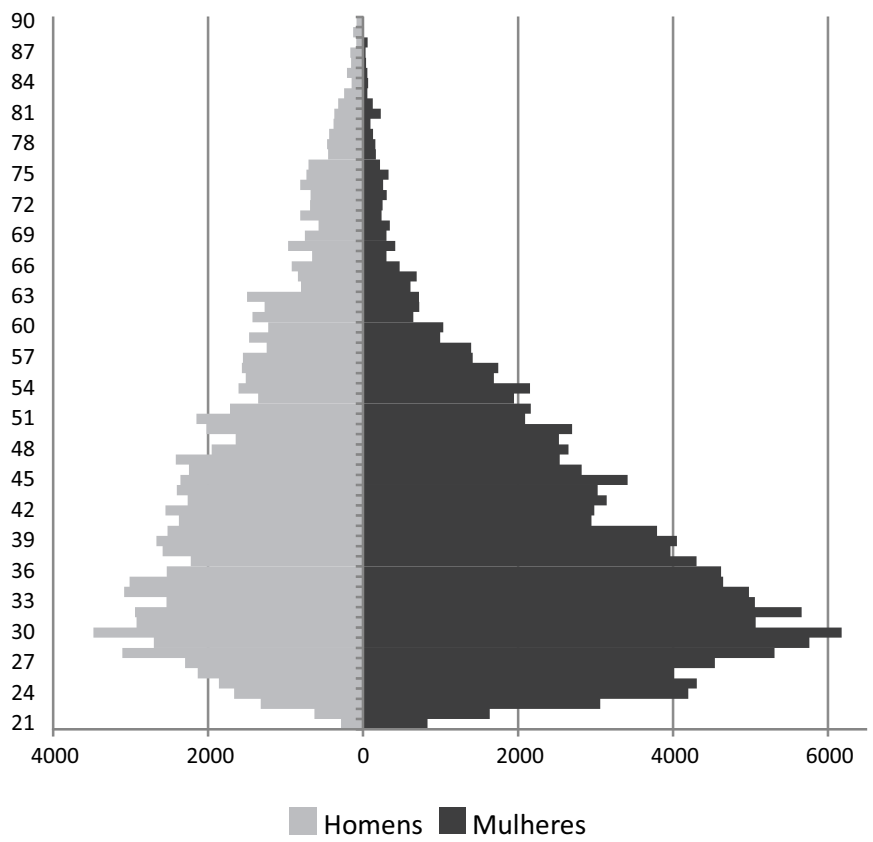

Fonte: elaboração própria, com base em dados do IBGE $(2002,2012)$. 


\section{Perfil da oferta segundo fluxos de formação}

Nos Gráficos de 4 a 6 está representada a evolução do número de vagas, ingressos e percentual de não preenchimento de vagas dos cursos de medicina, enfermagem e odontologia no Brasil, durante o período 1991 a 2012, segundo dados do Censo da Educação Superior do Instituto Nacional de Estudos e Pesquisas Educacionais Anísio Teixeira (Inep, 2013). ${ }^{2}$ No cômputo geral, no primeiro ano da série, as três áreas apresentaram ofertas de vagas em patamares muito próximos e com crescimento lento. A partir dos anos 2000, no entanto, o ritmo de crescimento acelerou, e na área da enfermagem observou-se um aumento significativo no número de vagas, distanciando-se da medicina e odontologia, que cresceram em ritmo semelhante, ainda que a odontologia um pouco acima. Durante todo o período foram criadas 10.145 vagas em medicina no país, o que representou um incremento bruto de 229,3\% (em números absolutos, aumento de 7.786 para 17.931 vagas). Em enfermagem criaram-se 125.783 vagas até o ano de 2010, $1.487,71 \%$ de aumento (de 7.460 para 133.243), mas nos anos seguintes, 2011 e 2012, foram fechadas 13.063 vagas. Em odontologia, por sua vez, a oferta cresceu 284,2\% até 2011, ou 13.546 novas vagas (de 7.315 para 20.861), tendo fechado 272 postos em 2012.

Esse salto trouxe consequências do ponto de vista do aproveitamento de vagas. Ao passo que em medicina o preenchimento de vagas se manteve constante, em enfermagem praticamente a metade das vagas foram desperdiçadas nos últimos anos da série, chegando ao ápice de 46,5\% em 2010 (133.243 vagas para 71.244 ingressos). É importante destacar que até 2003 o percentual de não preenchimento das vagas em enfermagem permaneceu constante e muito baixo. Com a expansão significativa no número de vagas a partir de 2000, no entanto, não se observou um acompanhamento do número de ingressos. Nos dois últimos anos da série, com o fechamento de vagas, o percentual de não preenchimento diminuiu, mas ainda continuou em níveis elevados. Em medicina a dinâmica é diferente, já que ao longo de todo o período assistiu-se à correspondência entre o número de ingressos e a oferta de novas vagas. Em odontologia também se observou um distanciamento entre as curvas de ingressos e de vagas, como visto em enfermagem, ainda que em números relativos e absolutos menores. Além disso, tal tendência se iniciou já no final da década de 1990 e alcançou seu pico em 2009, com 30,1\% de não preenchimento. Houve um recuo nos anos seguintes.

Em suma, os dados de formação apontam desperdício de vagas em enfermagem e odontologia, ainda que a procura pelos cursos tenha aumentado no período. Em outras palavras, a oferta de vagas nessas áreas foi superior à procura, mesmo em um período de crescimento da oferta geral de cursos superiores no Brasil e fundamentalmente de expansão do setor Saúde. Em medicina, ao contrário, o aumento da oferta esteve sempre acompanhado pela demanda correspondente, não havendo desperdício.

\footnotetext{
${ }^{2}$ Os dados detalhados podem ser consultados nas Tabelas 2, 3 e 4, no Apêndice.
} 
Gráfico 4 - Evolução do número de vagas e ingressos e percentual de não preenchimento de vagas de medicina. Brasil - 1991-2012

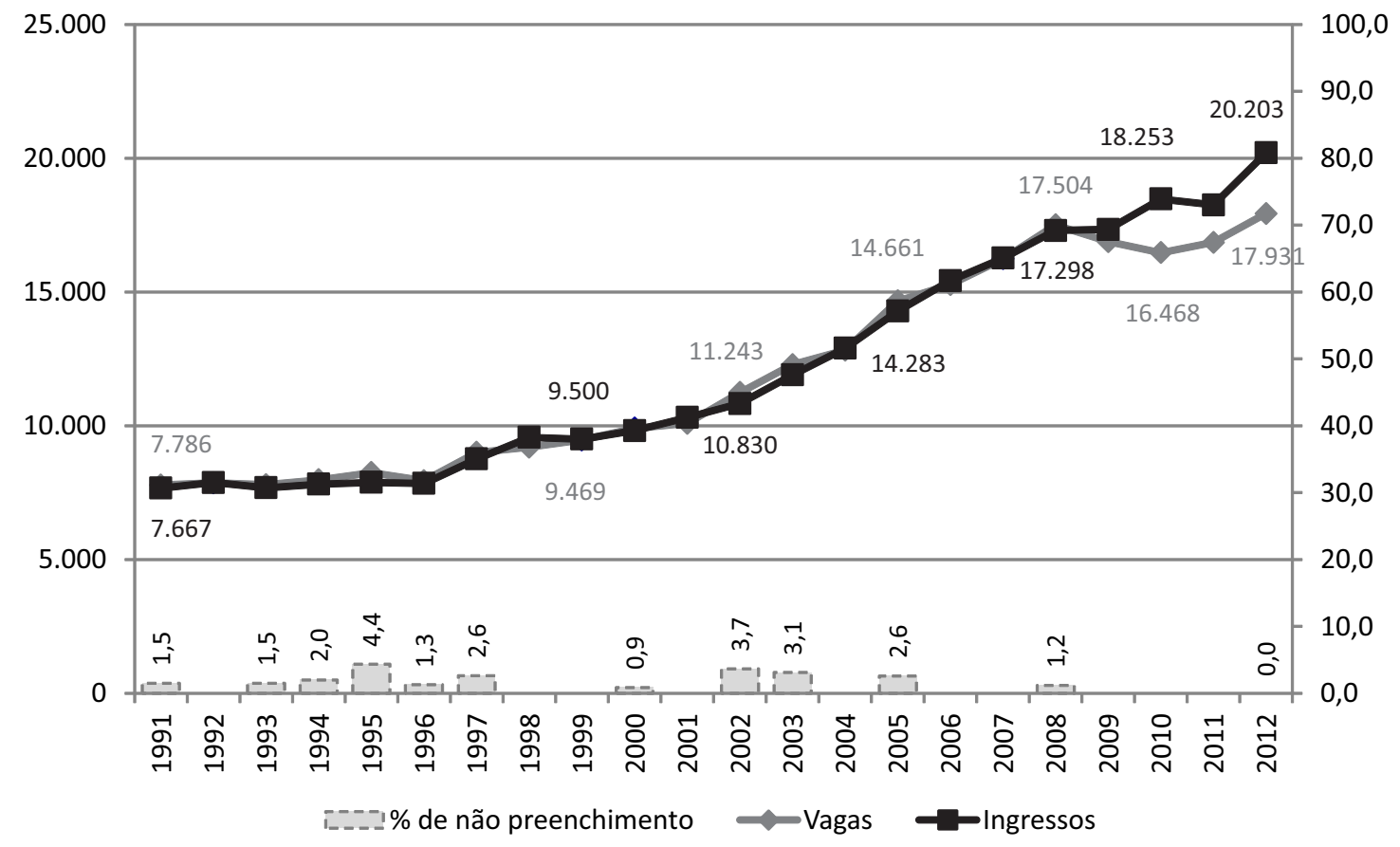

Fonte: elaboração própria, com base em dados do Inep (2013).

Gráfico 5 - Evolução do número de vagas e ingressos e percentual de não preenchimento de vagas de enfermagem. Brasil - 1991-2012

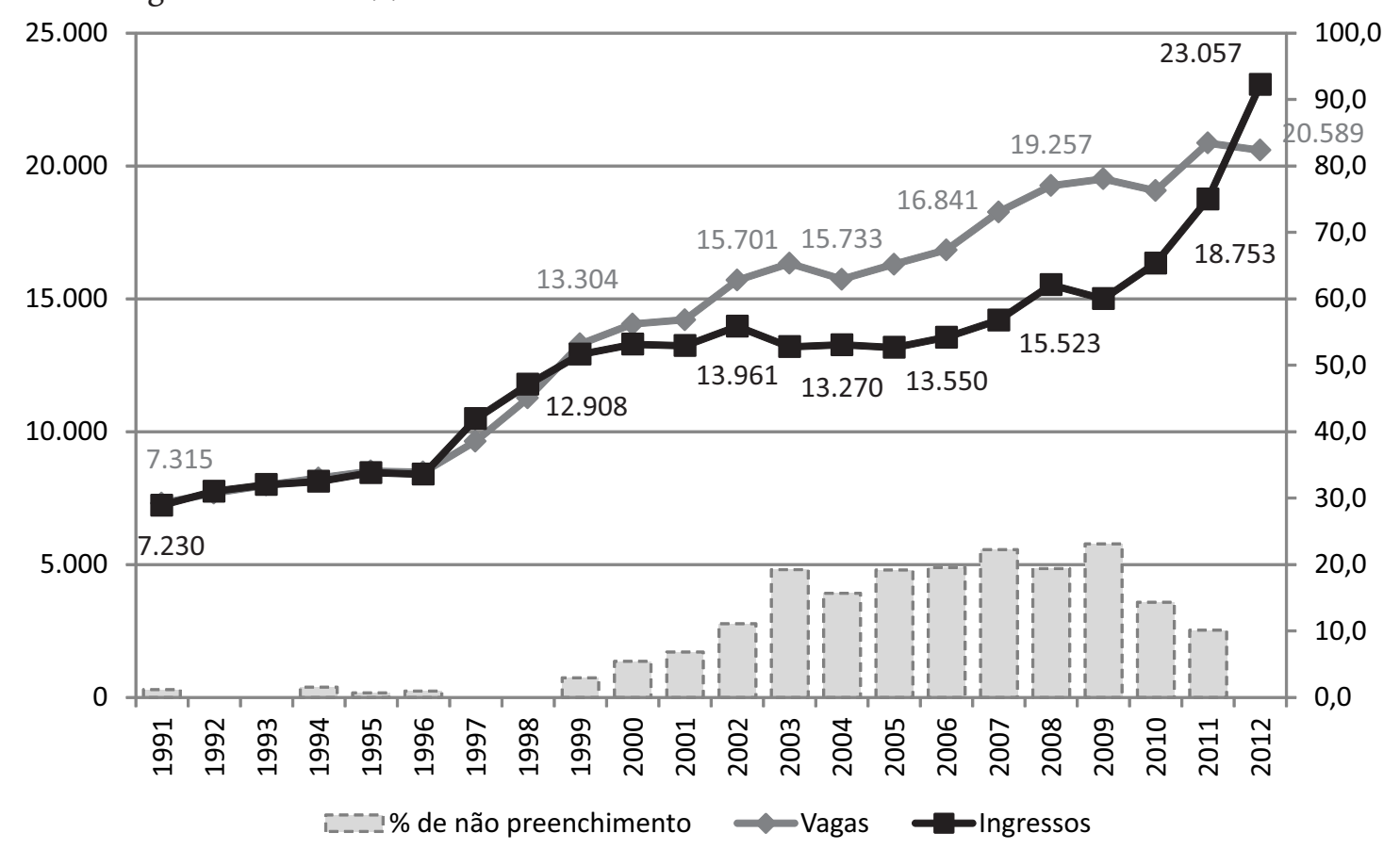

Fonte: elaboração própria, com base em dados do Inep (2013). 
Gráfico 6 - Evolução do número de vagas e ingressos e percentual de não preenchimento de vagas de odontologia. Brasil - 1991-2012

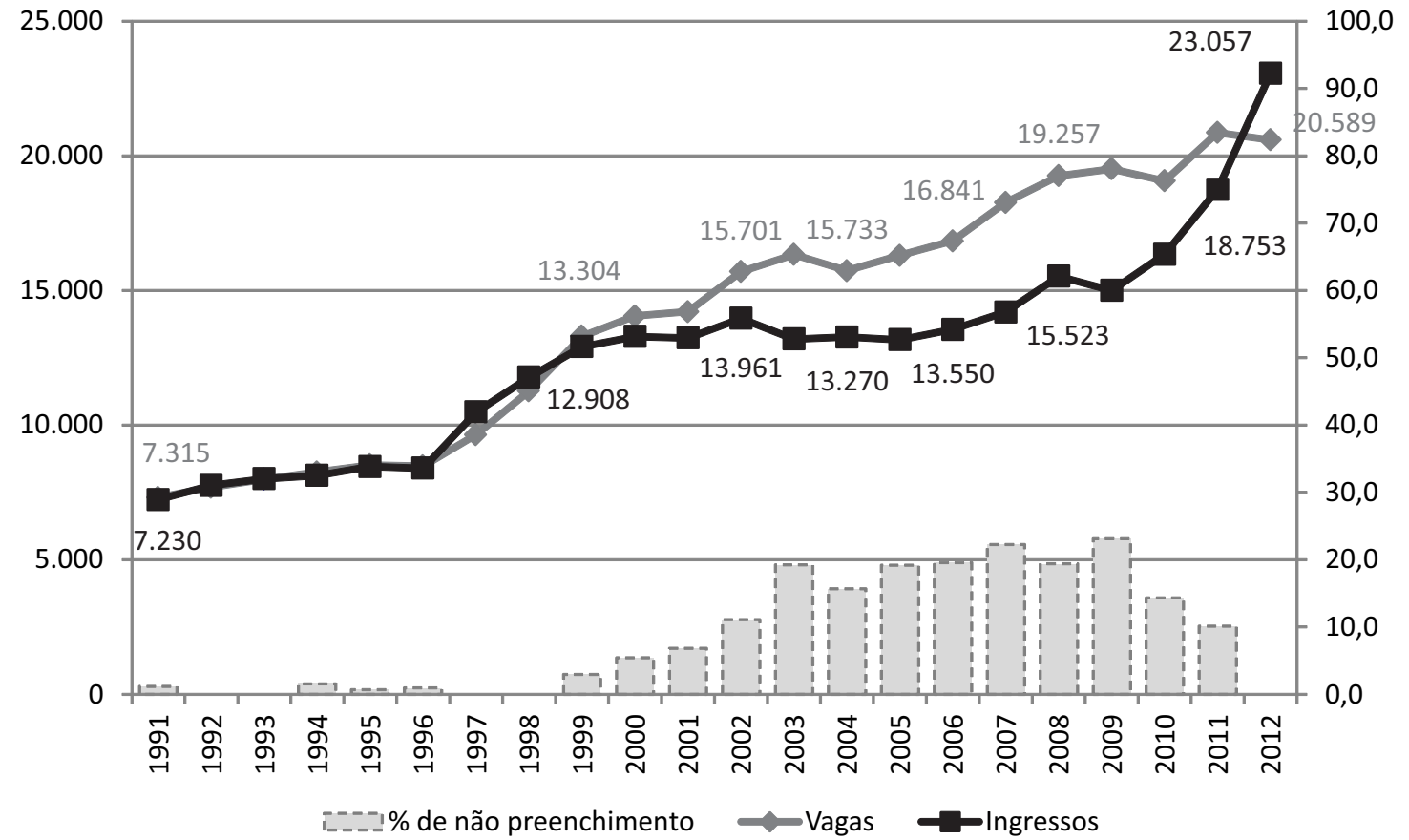

Fonte: elaboração própria, com base em dados do Inep (2013).

Nos Gráficos de 7 a 9, por sua vez, demonstra-se a evolução do número de ingressos, egressos e o percentual de não concluídos (taxa de eficiência terminal), durante o período de 1991 a 2012. Em medicina, os números de ingressos no ano $i$ e egressos no ano $i+6$ são bem próximos, indicando que a maioria dos estudantes que ingressam no curso conclui no tempo previsto. A variável percentual de não concluídos é pouco significativa ao longo do período, ainda que tenha aumentado a partir de 2007 em relação ao ano inicial de 2002, atingindo os maiores patamares entre 2008 e 2010. Nesse sentido, pode-se dizer que as escolas médicas, além de registrarem um bom aproveitamento entre a oferta e a demanda de vagas, também são "boas formadoras", pois há uma correspondência direta entre alunos que entram nos cursos e se tornam efetivos profissionais da área.

Assim como no quesito de aproveitamento de vagas, os cursos de enfermagem e odontologia têm comportamento semelhante quando se observa um hiato entre os ingressos no ano $i$ e os egressos no ano $i+5$. Entretanto, na odontologia esse hiato é observado desde os egressos de 2001, na enfermagem, a partir de 2006. No período em análise, o maior percentual (41,2\%) de não concluídos nos cursos de enfermagem ocorreu em 2010; nos cursos de odontologia, 38,9\% em 2006. Para esses cursos, portanto, vemos sinais de desperdício também ao longo do período previsto de formação, isto é, não só há um grande hiato entre oferta de vagas e procura pelo curso, como significativa desistência de graduandos. 
Gráfico 7 - Evolução de ingressos e egressos de medicina e taxa de eficiência terminal dos cursos. Brasil - 1991-1996 e 2007-2012

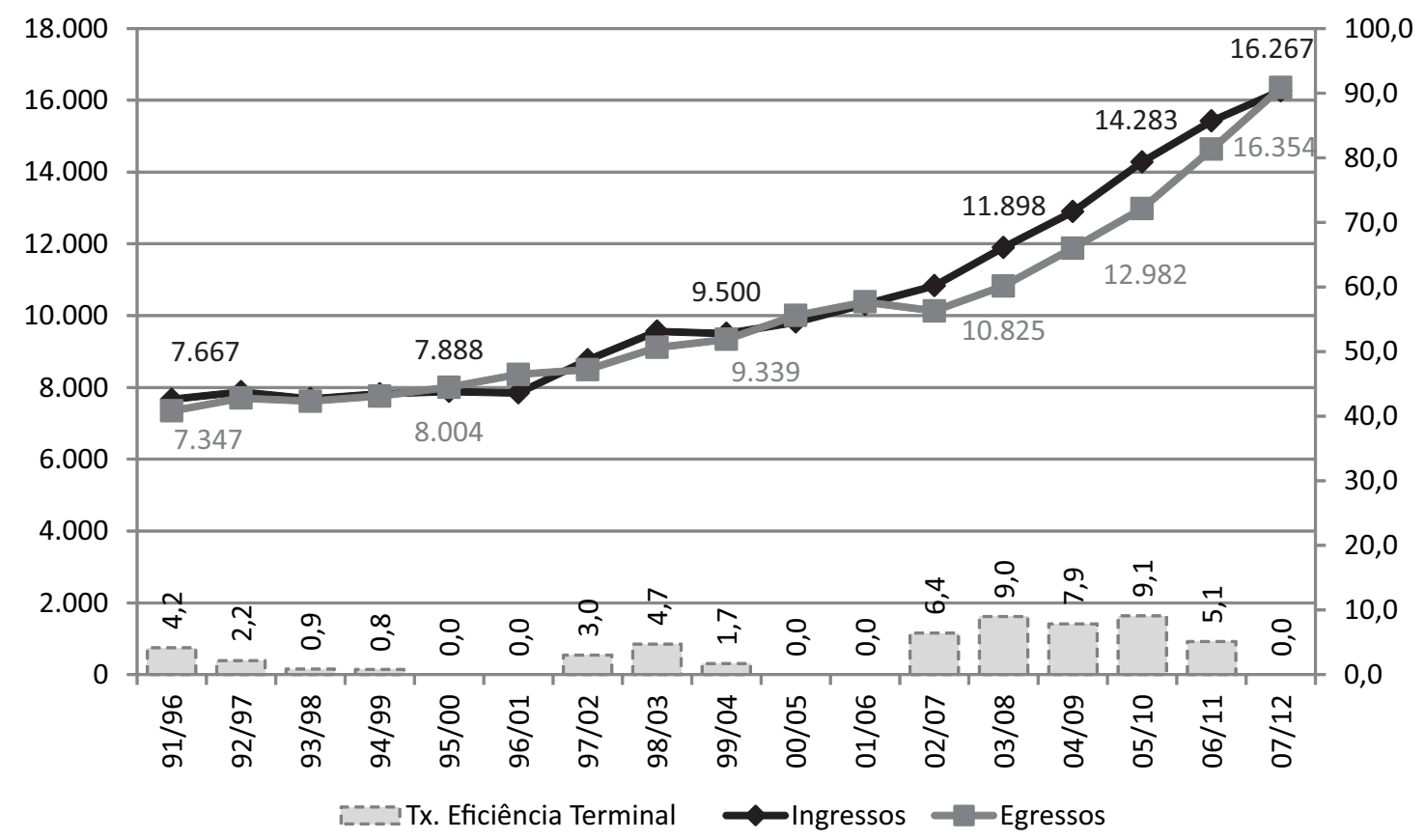

Fonte: elaboração própria, com base em dados do Inep (2013).

Gráfico 8 - Evolução de ingressos e egressos de enfermagem e taxa de eficiência terminal dos cursos. Brasil - 1991-1995 e 2008-2012

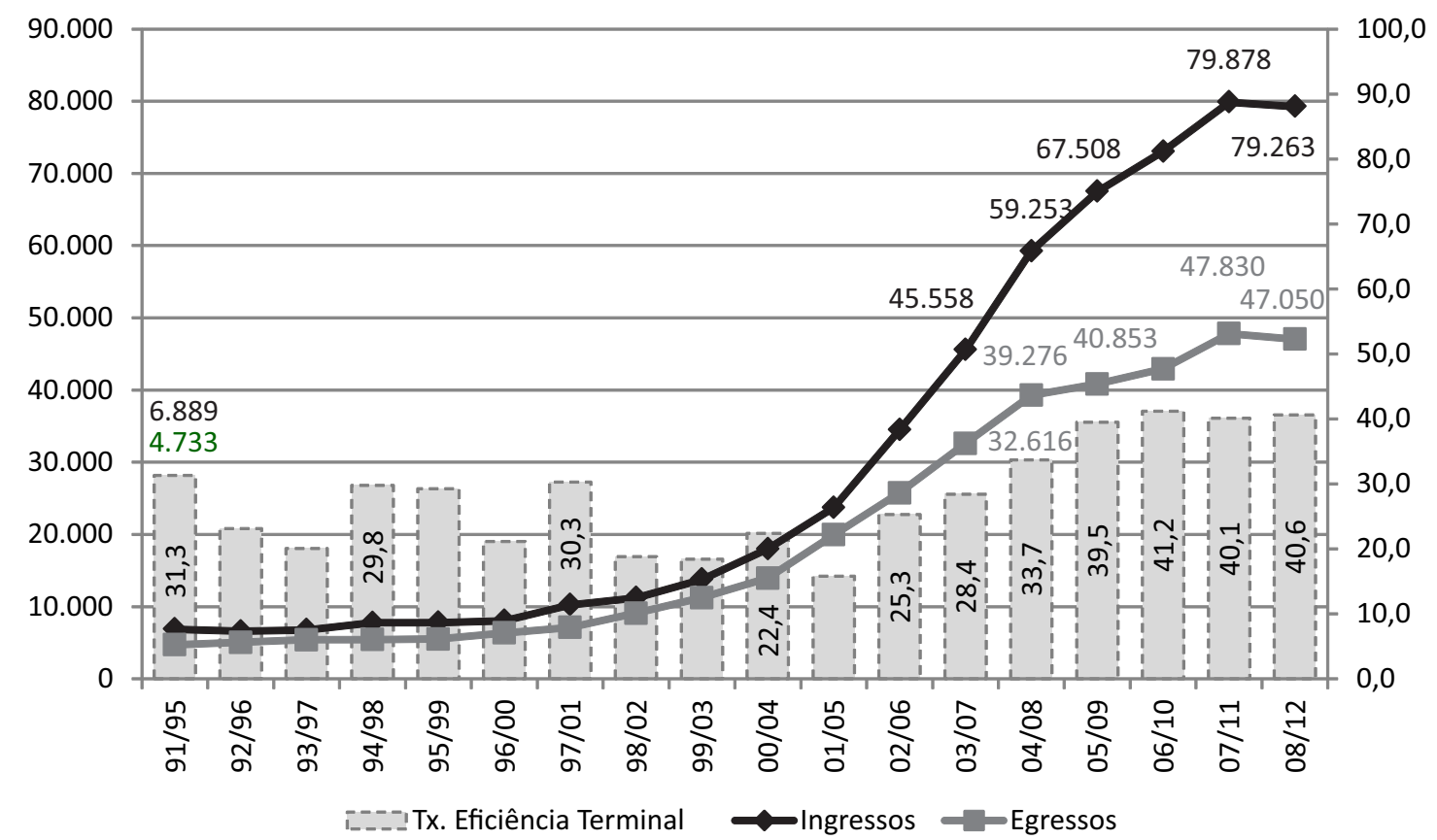

Fonte: elaboração própria, com base em dados do Inep (2013). 
Gráfico 9 - Evolução de ingressos e egressos de odontologia e taxa de eficiência terminal dos cursos. Brasil - 1991-1995 e 2008-2012

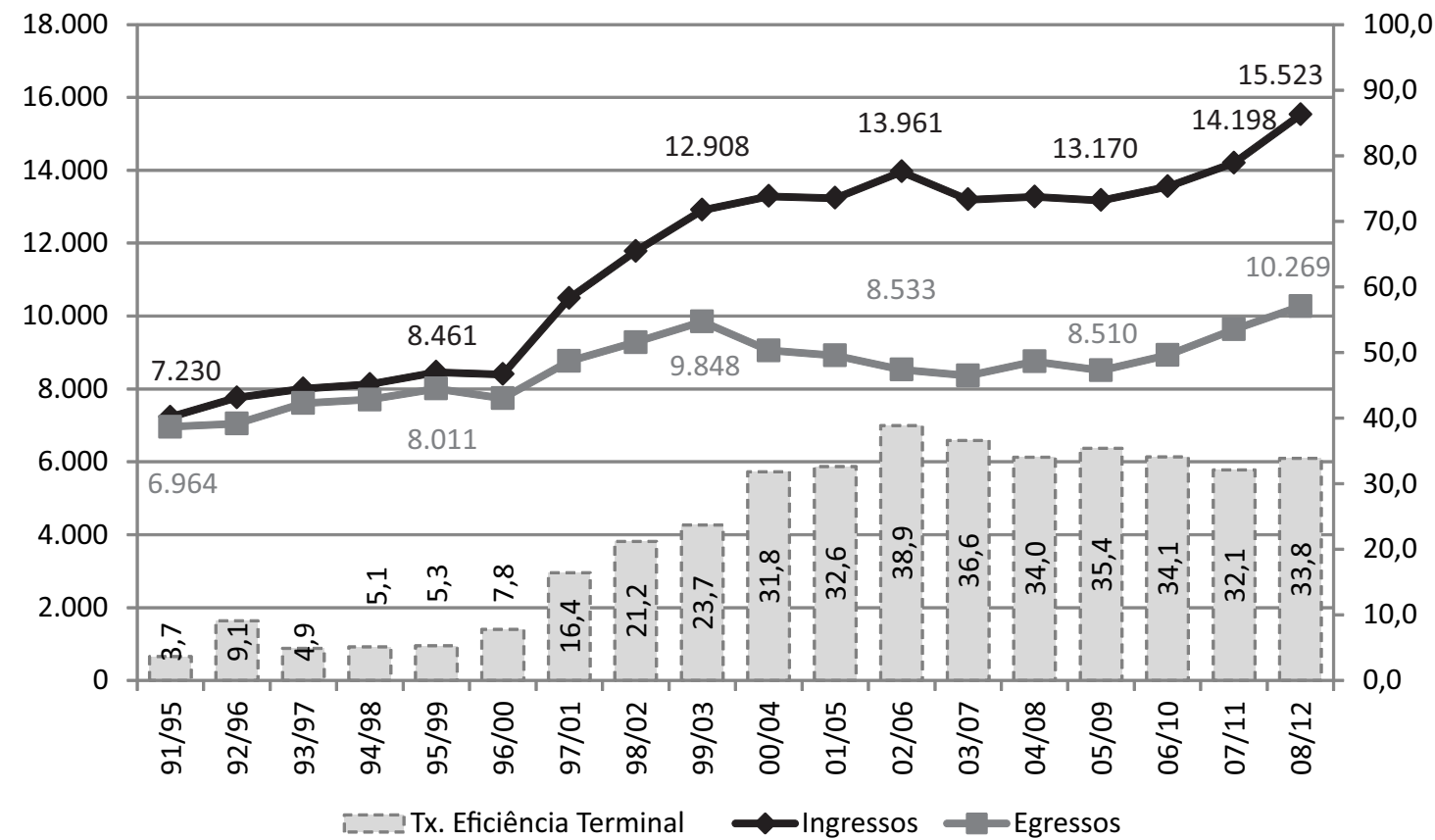

Fonte: elaboração própria, com base em dados do Inep (2013).

\section{Estimativas Futuras da Força de Trabalho}

\section{Sobre as técnicas e métodos}

Metodologias para a realização de previsões sobre a força de trabalho qualificada em saúde são relativamente escassas nos países em desenvolvimento, como afirma Rodrigues (2008), podendo citar para o caso de médicos, autores como Medina (1988) e Goic (1994, 1999), que desenvolveram uma metodologia de projeção baseada nas possibilidades de entrada e saída do profissional médico no mercado de trabalho. Existe também a metodologia proposta por Bevilacqua e Sampaio (2002) baseada em um modelo estatístico para a projeção de médicos segundo especialidades no Brasil. Um dos estudos mais recentes para vários países latino-americanos, entre eles o Brasil, é o de Barber Pérez, González López-Valcárcel e Suárez Vega (2011). No presente estudo, o cenário quantitativo do estoque de médicos, enfermeiros e cirurgiões-dentistas foi definido utilizando uma adequação da metodologia de projeções de população conhecida como "método das componentes demográficas", 3 anteriormente aplicada por Girardi e colaboradores (2012) apenas para médicos. Tal metodologia se baseia no conceito da equação compensatória e seus componentes que, de forma esquemática, ilustra-se na Figura 1.

\footnotetext{
${ }^{3}$ Para maiores detalhes sobre o Método das Componentes Demográficas, ver, por exemplo: Shryock e Siegel (1976), Celade (1984), Cedeplar (1999).
} 
Figura 1 - Equação compensatória para estimativas de recursos humanos

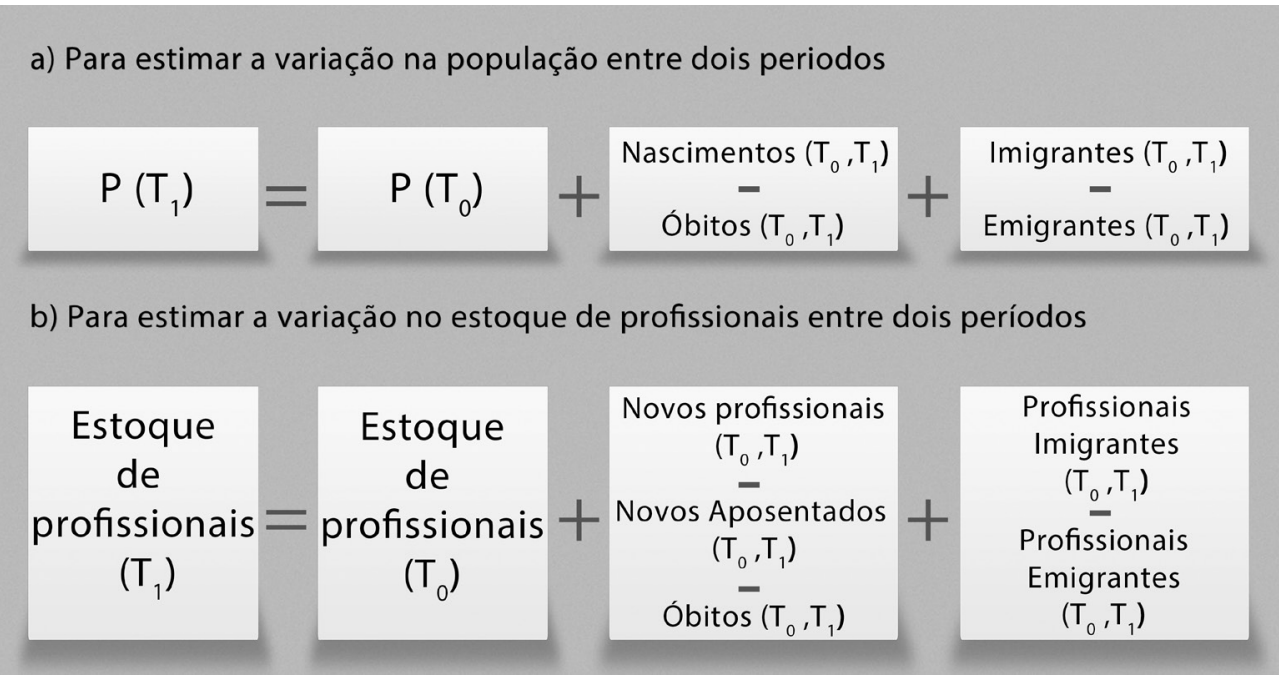

Fonte: Rodrigues, 2008.

O item a da Figura 1 explicita o processo de estimativa da população a partir de um período inicial $\left(\mathrm{T}_{0}\right)$ para um período seguinte $\left(\mathrm{T}_{1}\right)$, ao qual se adiciona uma nova população (no caso, nascimentos) e os demais eventos demográficos inerentes a uma coorte ou geração que se modifica aumentando ou diminuindo ao longo do tempo, seja por mortalidade (óbitos) e/ou fluxos migratórios. A adequação para estimar estoques de médicos é ilustrada no item b. Uma aplicação dessa adequação foi feita inicialmente por Rodrigues (2008) para Minas Gerais, na qual se empregaram também as estimativas de outros segmentos de força de trabalho qualificada (Pereira, Nascimento \& Araújo, 2013). Ressalta-se ainda que, seguindo o método das componentes demográficas, o esquema foi aplicado aos dados por sexo e idade. ${ }^{4}$

É importante esclarecer sobre a equação compensatória que, do ponto de vista conceitual, alguns aspectos mais complexos ficam de fora, como: a demanda e a necessidade de serviços de saúde, o impacto do desenvolvimento de novas tecnologias, a expansão da medicalização etc. Um elemento bastante determinante é a regulação profissional, podendo alterar (ampliar/diminuir) os escopos de prática de cada uma das profissões (Girardi et al., 2009). Apesar disso, exploram-se neste capítulo alguns cenários nos quais os estoques futuros de profissionais são adequados de acordo com alterações nos escopos de prática.

Para estimar a força de trabalho futura de médicos, enfermeiros e cirurgiões-dentistas seguindo a lógica da equação compensadora do método das componentes demográficas foi necessário estimar por profissão, sexo e idade: o número atual de profissionais economicamente ativos, isto é, a disponibilidade inicial, em 2010, de força de trabalho; o número de novos profissionais que se juntarão aos estoques iniciais e que derivam do sistema formativo das respectivas profissões, em outras palavras,

\footnotetext{
${ }^{4}$ Detalhes sobre a aplicação do método podem ser vistos em Rodrigues (2008).
} 
trata-se do número de nascimentos determinado pela quantidade e preenchimento das vagas em cursos de graduação e pelos níveis de conclusão dos cursos (comparação entre egressos e ingressos); o número de óbitos e as saídas por aposentadoria; e as entradas e saídas em razão da migração.

\section{Sobre os dados}

O primeiro componente da estimativa futura de profissionais é a definição do seu estoque inicial. O cálculo do número de profissionais da saúde é frequentemente feito a partir de um conjunto de bases de dados, buscando minimizar as dificuldades de contar aqueles que estão efetivamente disponíveis para o trabalho na assistência à saúde ou em atividades a ela relacionadas. O censo demográfico do IBGE se destaca, a priori, como a fonte que fornece o total de médicos, enfermeiros e cirurgiões-dentistas, estejam eles ocupados, desocupados ou não economicamente ativos, como se viu no tópico anterior. Neste caso, contam-se as pessoas que declararam ter graduação na área ou que estavam ocupadas no trabalho principal da semana de referência na profissão, sendo as duas condições não excludentes. ${ }^{5}$ Dessa forma, os valores podem ser superiores aos dos registros dos conselhos profissionais, em virtude da contagem de graduados na profissão que não possuem registro. Neste estudo utilizou-se o censo como referência para o cálculo do tamanho da população economicamente ativa das três profissões e sua composição por sexo e idade.

O segundo componente, isto é, o número de novos profissionais foi derivado dos dados de evolução da oferta, preenchimento de vagas (relação entre vagas e ingressos) e dos níveis de conclusão dos cursos de medicina, enfermagem e odontologia do Brasil, os quais provêm do Censo da Educação Superior do Inep. Utilizaram-se dois indicadores. De um lado, a razão entre número de inscritos por vaga - um importante indicador, pois o aumento da procura pelo curso, mesmo com o crescimento do número de vagas, destaca que a profissão é bem vista na percepção dos pretendentes à profissão, do ponto de vista vocacional e também econômico. Por outro lado, a chamada taxa de eficiência terminal da graduação. Essa taxa é medida pela relação entre o número de ingressos no ano $i$ e de egressos no ano $i+n$, sendo $n$ o número de anos de duração do curso, menos 1 . Expressa através de percentual, tal proporção não pode ser confundida com a verificação do número de alunos que não se formaram dentre aqueles que ingressaram. A proporção expressa a não conclusão no período provável de formação em relação ao volume de ingressantes e concluintes nos dois períodos em análise, seja por atraso ou desistência.

Os números de óbitos foram obtidos indiretamente considerando como evidência os dados da Rais de 2010 (Brasil, 2011), aplicando-se ao estoque atual as probabilidades de morte decorrentes de tabelas de sobrevivência. Não existe claro consenso sobre diferenciais de mortalidade adulta segundo composição profissional, embora um bom número de estudos coincida em indicar níveis de mortalidade menores para grupos como médicos e cirurgiões-dentistas. Presume-se que essas categorias

\footnotetext{
${ }^{5}$ Contam-se graduados e ocupados na profissão; graduados na profissão, mas ocupados em outra função; e os ocupados na profissão, sem informação de graduação na área (Destacando que o registro de curso de graduação no censo ocorre para a última graduação concluída pelo entrevistado e desde que o maior nível de formação seja o de graduação. Dessa forma não é possível saber a graduação dos pós-graduados). Os dados foram consistidos, tendo sido desconsiderados os casos de entrevistados identificados nas três profissões que não tivessem nível superior completo ou idade mínima de 22 anos, no caso de médicos; e de 21 anos, no caso de enfermeiros e cirurgiões-dentistas.
} 
profissionais, por terem educação superior e acesso mais facilitado a bens de consumo, apresentam menores níveis de mortalidade que os definidos para a média do cidadão brasileiro, o que pode ocorrer de forma diferente para enfermeiros. Assim, calculou-se o diferencial dos riscos de morte por sexo e idade entre os indivíduos classificados como médicos, enfermeiros e cirurgiões-dentistas e o restante dos trabalhadores, cada um em seu momento, por meio da Rais. O mesmo diferencial foi aplicado à tábua de mortalidade do total do país para aquele ano, assumindo que essa é representativa dos profissionais em questão e de um sistema de tábuas-modelo. ${ }^{6}$

A população total do Brasil estimada para os períodos considerados, salvo especificação contrária, foi a definida pelo Centro de Desenvolvimento e Planejamento Regional da UFMG (Cedeplar, 2012).

\section{Sobre os pressupostos adotados para as projeções}

No exercício de estimativa para os anos de 2010 a 2030, assumiu-se como população inicial o número de residentes no país em 2010 aptos ao exercício da profissão, para o qual se estabeleceu um corte de acordo com a condição de atividade. Dessa forma, incluíram-se todos os economicamente ativos (ocupados e desocupados), independentemente da idade. Em razão das diferenças demográficas e de oferta e demanda de cada profissão, procedeu-se a um modelo para cada caso com pressupostos e cenários distintos, os quais são apresentados a seguir:

- O número de novos profissionais que se juntarão aos estoques existentes está estreitamente associado a uma cadeia de eventos que historicamente mostram associação e regularidade. Tal cadeia começa com o planejamento e posterior pedido de vagas para admissão de novos alunos às escolas. Uma vez que se autoriza a abertura de vagas, estas se cristalizam em matrículas que após o período regular de duração do curso refletem um número de egressos. No caso da medicina, após seis anos o número de egressos foi praticamente constante em relação ao número original de vagas, no período de 1991-1996 a 2007-2012, apresentando uma taxa de eficiência terminal média de 90\%. Já para enfermagem e odontologia, com cinco anos se observa uma distância maior entre egressos e vagas correspondentes, no período de 1991-1995 a 2008-2012, o que reflete um alto abandono do curso, principalmente na segunda metade da década de 2000. Em média, as taxas foram de $72 \%$ e $77 \%$, respectivamente.

- O volume de profissionais no Brasil entre 2010 e 2015 está praticamente definido principalmente pela formação dos estudantes de medicina que se matricularam entre 20032004 a 2009-2010 e pelos estudantes de enfermagem e odontologia que se matricularam entre 2004-2005 a 2009-2010. Esse volume variará ligeiramente em razão do percurso da migração e da mortalidade, esta última, afetando minimamente a variação do estoque. Para os anos posteriores a 2015, o volume poderá divergir caso venha a se registrar variação do número de vagas que as universidades oferecerão para os anos posteriores a 2010, o que foi definido por meio de cenários hipotéticos abordados adiante.

\footnotetext{
${ }^{6}$ A tabela de mortalidade para o país é aquela definida pelo IBGE (IBGE, 2009). O sistema de tábuas-modelo de mortalidade utilizado foi o de Coale e Demeny (Modelo Oeste), que é o que com mais frequência costuma se ajustar melhor à experiência de mortalidade dos países em desenvolvimento (Coale \& Demeny, 1983).
} 
- Definiu-se que, se a média dos trabalhadores apresenta uma esperança de vida similar à correspondente ao total do país para 2010, os médicos e cirurgiões-dentistas, respeitando os diferenciais encontrados na Rais, teriam uma esperança de vida superior em aproximadamente quatro anos (Tabela 1 do Apêndice), com ligeira vantagem para o sexo feminino; e os enfermeiros teriam uma esperança de vida similar, também respeitando a análise realizada pela Rais. Ressalte-se que essa decisão, embora subjetiva e suscetível a melhoras, pouco afeta o resultado final, uma vez que na população economicamente ativa o número de óbitos esperados variará muito pouco, qualquer que seja o nível de mortalidade definido.

- As saídas por aposentadoria, quando significam saída definitiva do mercado de trabalho, não foram consideradas uma vez que o modelo admite apenas a população economicamente ativa.

- Quanto às entradas e saídas em consequência da migração, presume-se que o estoque de profissionais alterar-se-á em virtude da migração da mesma forma em que o Brasil é afetado. As evidências disponíveis sugerem que o saldo migratório internacional de profissionais da saúde tem sido tradicionalmente irrelevante, daí que, neste exercício, se considere que o volume total da força de trabalho das profissões em questão seja desprezível. A validade dessa decisão será revisada, evidentemente, à luz dos próximos censos demográficos.

\section{Cenários e resultados}

\section{Médicos}

Na construção dos componentes que constituem o estoque de profissionais explicitado no item anterior, o volume de médicos economicamente ativos no Brasil para o período entre 2010 e 2015 foi definido, principalmente, com base na formação dos estudantes de medicina que se matricularam entre 2003-2004 a 2009-2010. Esse volume varia ligeiramente em função do comportamento da migração e da mortalidade, esta última, afetando minimamente a variação do estoque. Para os anos posteriores a 2015, o volume poderá divergir caso seja registrada variação de monta no número de vagas efetivamente ofertadas nos anos posteriores a 2012, como é o caso do que se desenha a partir do Programa Mais Médicos do Governo Federal (Brasil, 2013). Assim, há possibilidade de se vislumbrar alguns cenários que podem determinar a futura variação desse estoque:

- Cenário tendencial: com base no comportamento que as escolas de medicina do país apresentaram no período entre 1991 e 2012, em relação ao número anual de vagas, assumese que o crescimento de 3,4\%, não será sustentado. De fato, no último quadriênio, entre 2009 e 2012, as vagas cresceram em um patamar menor, de 2,4\% ao ano. Assume-se, nesse cenário, que as vagas manterão um ritmo menor de crescimento e passarão de 17.931, em 2012, para 24.161, em 2024. O volume de novos médicos até 2030, portanto, aumentará a partir dessa tendência. Além disso, em média, a taxa de eficiência terminal do curso será de $84 \%$, e a razão de ingresso por vaga será de 1,0, valores que também foram observados para o último quadriênio.

- Cenário Mais Médicos: o segundo cenário é baseado na oferta de novas vagas previstas no Programa Mais Médicos num total de 12.761 entre 2013 e 2017 (sendo 1.762 em 2013, 
2.912 em 2014, 4.242 em 2015, 3.619 em 2016 e 226 em 2017). ${ }^{7}$ A partir de 2018, prevê-se que o número total de vagas resultante, que passará de 17.931 para 30.692, permanecerá constante sem a intervenção do Programa. As tendências quanto ao preenchimento das vagas e à conclusão do curso no tempo previsto serão aquelas observadas entre 2003 e 2012, isto é, taxa de eficiência terminal de $87 \%$ e razão de ingresso por vaga de 1,0 .

- Cenário sem crescimento: como comparação, um terceiro cenário implicará manter o número de vagas anuais entre 2010-2015 constante até 2030, isto é, sem alteração. Além disso, a eficiência terminal e o preenchimento de vagas permanecerão como observados no último quadriênio.

Esses cenários resultam, para 2030, em estoques oscilando entre 552,9 e 668,7 mil profissionais médicos para Brasil (Tabela 3). No caso do cenário tendencial, esperar-se-ia que a atual RMH, de 1,72 médico por cada mil habitantes em 2010, passasse para 2,57 em 2030. A razão ficaria em 2,46 no cenário de crescimento zero do número de vagas e em 2,98 no cenário do Programa Mais Médicos. A composição por idade obtida no cenário tendencial indica que a diferença por sexo tenderá a cair, visto que o número de vestibulandos e estudantes segundo sexo tende a ser igual, com ligeira tendência ao maior aumento entre as mulheres.

Tabela 3 - Brasil 2010-2030: número de médicos, incremento médio anual e razão por mil habitantes

\begin{tabular}{|c|c|c|c|c|c|}
\hline Cenários & 2010 & 2015 & 2020 & 2025 & 2030 \\
\hline \multicolumn{6}{|c|}{ a) Médicos } \\
\hline Cenário 1 (tendencial) & 328.006 & 383.652 & 440.021 & 505.897 & 577.707 \\
\hline Cenário 2 (Mais Médicos) & 328.006 & 384.681 & 444.477 & 553.692 & 668.767 \\
\hline Cenário 3 (sem crescimento) & 328.006 & 385.922 & 443.850 & 501.287 & 552.983 \\
\hline \multicolumn{6}{|c|}{ b) Incremento médio anual do n. de novos profissionais } \\
\hline Cenário 1 (tendencial) & & 11.129 & 11.274 & 13.175 & 14.362 \\
\hline Cenário 2 (Mais Médicos) & & 11.335 & 11.959 & 21.843 & 23.015 \\
\hline Cenário 3 (sem crescimento) & & 11.583 & 11.586 & 11.487 & 10.339 \\
\hline \multicolumn{6}{|c|}{ c) N. de profissionais por mil habitantes } \\
\hline Cenário 1 (tendencial) & 1,72 & 1,88 & 2,07 & 2,30 & 2,57 \\
\hline Cenário 2 (Mais Médicos) & 1,72 & 1,89 & 2,09 & 2,52 & 2,98 \\
\hline Cenário 3 (sem crescimento) & 1,72 & 1,89 & 2,09 & 2,28 & 2,46 \\
\hline
\end{tabular}

Fonte: elaboração própria, com base em metodologia específica.

\section{Enfermeiros}

Os cenários desenhados para enfermeiros são os seguintes:

- Cenário tendencial: com base no comportamento que as escolas de Enfermagem do país apresentaram no período entre 1991 e 2012, em relação ao número anual de vagas, assume-

\footnotetext{
7 Dados do cadastro do Programa Mais Médicos de fevereiro de 2016 obtidos por solicitação especial ao Departamento de Gestão da Educação em Saúde da Secretaria de Gestão do Trabalho e da Educação em Saúde do Ministério da Saúde.
} 
se que o crescimento de $13,7 \%$ ao ano não será sustentado. De fato, no último quadriênio, entre 2009 a 2012, as vagas decresceram a 2,1\% ao ano. Assume-se que as vagas manterão esse ritmo de fechamento e passarão de 120.180, em 2012, para 83.962, em 2025. O número de novos enfermeiros, portanto, acompanhará tal tendência sofrendo desaceleração em seu crescimento até 2030. Além disso, em média, a taxa de eficiência terminal será de 64\% e a razão de ingresso por vaga de 0,63 , valores que também foram observados para o último quadriênio.

- Cenário regulatório: é baseado na reversão do quadro atual de fechamento de vagas nos cursos de enfermagem, buscando estabelecer volumes de profissionais que no futuro possam cobrir um escopo de prática ampliado da profissão (por exemplo, em anestesia, obstetrícia e geriatria), bem como a expansão das atividades da ESF, a qual passaria a exigir a presença de dois enfermeiros por equipe. Ainda que os mais de $50 \%$ da força de trabalho graduada em enfermagem não ativa na profissão passem a sê-lo, supõe-se que ainda assim não será suficiente para atender o novo cenário regulatório suposto. Assim, prevê-se a mesma tendência observada entre 2003 e 2012, isto é, crescimento de vagas de 9,1\% ao ano até 2017 (passando de 120.180 para 171.559), eficiência terminal de $86 \%$ e razão de ingressos por vaga de 0,75 .

- Cenário sem crescimento: como comparação, um terceiro cenário implicará manter o número de vagas anuais observado em 2012 constante até 2030, isto é, sem incremento. A eficiência terminal e o preenchimento de vagas permaneceriam como no último quadriênio.

Tais cenários resultam, para 2030, em estoques oscilando de 1,073 a 1,970 milhão de enfermeiros para Brasil (Tabela 4). No caso do cenário tendencial, esperar-se-ia que a razão de 1,59 enfermeiro por cada mil habitantes em 2010, passasse para 4,78 em 2030. A razão ficaria em torno de 5,61 no cenário de crescimento zero do número de vagas e 8,77 no cenário regulatório.

Tabela 4 - Brasil 2010-2030: número de enfermeiros, incremento médio anual e razão por mil habitantes

\begin{tabular}{|c|c|c|c|c|c|}
\hline Cenários & 2010 & 2015 & 2020 & 2025 & 2030 \\
\hline \multicolumn{6}{|c|}{ a) Enfermeiros } \\
\hline Cenário 1 (tendencial) & 308.429 & 492.630 & 713.892 & 907.186 & 1.073 .915 \\
\hline Cenário 2 (regulatório) & 308.429 & 588.531 & 954.632 & 1.440 .372 & 1.970 .500 \\
\hline Cenário 3 (sem crescimento) & 308.429 & 557.773 & 843.510 & 1.054 .183 & 1.258 .893 \\
\hline \multicolumn{6}{|c|}{ b) Incremento médio anual do n. de novos profissionais } \\
\hline Cenário 1 (tendencial) & & 36.840 & 44.252 & 38.659 & 33.346 \\
\hline Cenário 2 (regulatório) & & 56.021 & 73.220 & 97.148 & 106.026 \\
\hline Cenário 3 (sem crescimento) & & 49.869 & 57.147 & 42.135 & 40.942 \\
\hline \multicolumn{6}{|c|}{ c) N. de profissionais por mil habitantes } \\
\hline Cenário 1 (tendencial) & 1,59 & 2,42 & 3,36 & 4,13 & 4,78 \\
\hline Cenário 2 (regulatório) & 1,59 & 2,89 & 4,49 & 6,56 & 8,77 \\
\hline Cenário 3 (sem crescimento) & 1,59 & 2,74 & 3,97 & 4,80 & 5,61 \\
\hline
\end{tabular}

Fonte: elaboração própria, com base em metodologia específica. 


\section{Cirurgiões-dentistas}

Os cenários desenhados para cirurgiões-dentistas são os seguintes:

- Cenário tendencial: com base no comportamento que os cursos de odontologia do país apresentaram entre 1991 e 2012, em relação ao número anual de vagas, assume-se que o crescimento de 5,1\% ao ano não se sustentará. De fato, no último quadriênio, entre 2009 a 2012, as vagas cresceram a 2,0\% ao ano. Assume-se que as vagas manterão esse ritmo menor de crescimento e passarão de 20.589, em 2012, para 26.500, em 2025. O número de novos cirurgiões-dentistas acompanhará tal tendência. A taxa de eficiência terminal será de 69\% e a razão de ingresso por vaga de 0,91, valores que também foram observados para o último quadriênio.

- Cenário regulatório: é baseado na reversão do quadro atual de desaceleração do crescimento de vagas com o objetivo de estabelecer volumes de profissionais que no futuro possam cobrir uma demanda reprimida na área, neste caso, prevendo a universalização dos serviços de saúde bucal no SUS, sem que se alterem substancialmente os serviços privados. Prevê-se a mesma tendência observada entre 1991 e 2012, isto é, crescimento de vagas de 5,1\% ao ano (passando de 20.589, em 2012, para 39.237, em 2025). Além da ampliação no número de vagas, este cenário inclui intervenções nos níveis de aproveitamento de vagas e conclusão do curso, considerando uma razão de ingresso por vaga de 0,9 e taxa de eficiência terminal de 90\%.

- Cenário sem crescimento: como comparação, um terceiro cenário implicará manter o número de vagas anuais observado em 2012 constante até 2030, com eficiência terminal e preenchimento das vagas similar ao último quadriênio.

Esses cenários resultam, para 2030, em estoques oscilando de 439 a 562,4 mil cirurgiões-dentistas para o Brasil (Tabela 5). No caso do cenário tendencial, esperar-se-ia que a razão de 1,11 cirurgiãodentista por cada mil habitantes em 2010, passasse para 1,96 em 2030. A razão ficaria em torno de 1,99 no cenário de crescimento zero do número de vagas e 2,50 no cenário regulatório.

Tabela 5 - Brasil 2010-2030: número de cirurgiões-dentistas, incremento médio anual e razão por mil habitantes

\begin{tabular}{|c|c|c|c|c|c|}
\hline Cenários & 2010 & 2015 & 2020 & 2025 & 2030 \\
\hline \multicolumn{6}{|c|}{ a) Cirurgiões-dentistas } \\
\hline Cenário 1 (tendencial) & 214.909 & 263.299 & 317.203 & 376.449 & 439.098 \\
\hline Cenário 2 (regulatório) & 214.909 & 279.653 & 353.195 & 445.291 & 562.423 \\
\hline Cenário 3 (sem crescimento) & 214.909 & 273.723 & 342.546 & 396.449 & 446.641 \\
\hline \multicolumn{6}{|c|}{ b) Incremento médio anual do $\mathrm{n}$. de novos profissionais } \\
\hline Cenário 1 (tendencial) & & 9.678 & 10.781 & 11.849 & 12.530 \\
\hline Cenário 2 (regulatório) & & 12.949 & 14.708 & 18.419 & 23.426 \\
\hline Cenário 3 (sem crescimento) & & 11.763 & 13.765 & 10.781 & 10.038 \\
\hline \multicolumn{6}{|c|}{ c) N. de profissionais por mil habitantes } \\
\hline Cenário 1 (tendencial) & 1,11 & 1,29 & 1,49 & 1,71 & 1,96 \\
\hline Cenário 2 (regulatório) & 1,11 & 1,37 & 1,66 & 2,03 & 2,50 \\
\hline Cenário 3 (sem crescimento) & 1,11 & 1,34 & 1,61 & 1,81 & 1,99 \\
\hline
\end{tabular}

Fonte: elaboração própria, com base em metodologia específica. 


\section{Considerações Finais}

O presente capítulo teve por objetivo apresentar as estruturas e as estimativas dos quantitativos de médicos, enfermeiros e cirurgiões-dentistas no Brasil entre 2010 e 2030 . A metodologia utilizada, quando aplicada às populações de profissionais de nível superior, tem dado resultados consistentes. A qualidade e oportunidade dos censos de população e do ensino superior, comparativamente à relativa precariedade de outros sistemas estatísticos, justificam o uso da metodologia demográfica aqui adaptada. Além disso, a flexibilidade de se desenharem cenários hipotéticos permite considerar aspectos relativos à demanda futura por recursos humanos da saúde, elemento que não é explorado diretamente em outros modelos.

Em relação à medicina, a análise dos dados sugere uma tendência pregressa a 2010 de crescimento contido da oferta de vagas na graduação, resultando em uma razão de 1,72 médico por mil habitantes naquele ano. Do ponto de vista demográfico, assistiu-se a um aparente paradoxo, constituído pela concomitância entre um forte rejuvenescimento da força de trabalho ao lado de seu envelhecimento em razão do elevado tempo médio de permanência dos profissionais no exercício da profissão e do prolongado período de relativa estagnação do número de vagas nos anos 1980 e primeira metade dos anos 1990. Observou-se ainda ampliação da participação feminina, embora insuficiente para que os homens deixassem de ser a maioria. A grande oferta de oportunidades de trabalho e serviços médicos, o crescimento do emprego formal e dos salários e o pleno aproveitamento das vagas oferecidas pelos cursos de medicina nos anos recentes corroboram os diagnósticos de escassez e justificam a adoção de políticas de ampliação da oferta de médicos, a exemplo do Mais Médicos. Os resultados das projeções, em quaisquer dos cenários analisados, indicam escassez de médicos no futuro. Nem mesmo no cenário de maior expansão e adequação da distribuição regional da oferta de vagas e cursos (Mais Médicos), a questão da escassez seria afastada, ainda mais se considerarmos o crescimento das demandas decorrentes do envelhecimento populacional e das mudanças epidemiológicas, tecnológicas e organizacionais em curso em nosso país.

A enfermagem representou uma situação oposta à da medicina, na medida em ampliou expressivamente a oferta de vagas nos cursos de graduação e a população de diplomados nos anos 2000 . O fato de ter uma composição majoritariamente feminina, associado ao expressivo rejuvenescimento ocorrido naquela década e a dependência de uma trajetória assalariada típica no mercado de trabalho acarretaram uma exposição minoritária de enfermeiros diplomados ao exercício efetivo da profissão. A taxa de 1,59 enfermeiro por mil habitantes em 2010, portanto, deve ser reduzida a menos da metade para que se considere a disponibilidade real de profissionais para os serviços de saúde. Embora as vagas nos cursos de enfermagem tenham começado a declinar a partir de 2011, o cenário tendencial assinala uma taxa de 4,78 enfermeiros por mil habitantes em 2030, mesmo com a manutenção de baixas taxas de aproveitamento de vagas e de eficiência terminal dos cursos. Tal razão, no entanto, só se mostrará relevante caso aumente a proporção de pessoas ocupadas na profissão. Note-se que um cenário ainda mais expansivo poderia ser considerado, com uma razão de 8,77 profissionais por mil habitantes em uma conjuntura de ampliação de escopos de práticas em áreas como obstetrícia, anestesiologia, geriatria e saúde da família. 
A odontologia, por sua vez, apresentou uma situação próxima à da medicina, com o crescimento mais contido das vagas de graduação e processos concomitantes de rejuvenescimento, envelhecimento e feminilização da população economicamente ativa. Entretanto, a odontologia apresentou um quantitativo menor de profissionais, com um aproveitamento bem menor das vagas existentes e baixa participação no mercado de trabalho formal, além de uma maioria feminina, em que pese a existência de enorme demanda pelos serviços de saúde bucal do SUS. Assim, contra uma razão de 1,1 profissional por mil habitantes em 2010, prevê-se um cenário regulatório com uma razão de 2,5 em 2030, o qual se esperaria atender às atuais demandas de acesso universal e integral aos serviços de saúde bucal, sem que se alterasse substancialmente a disponibilidade de profissionais no mercado privado.

\section{Referências}

BARBER PÉREZ, P.; GONZÁLEZ LÓPEZ-VALCÁRCEL, B. \& SUÁREZ VEGA, R. Oferta, Demanda y Necesidad de Médicos Especialistas en Brasil: proyecciones a 2020. Las Palmas: Universidad de Las Palmas de Gran Canaria, 2011.

BEVILACQUA, R. G. \& SAMPAIO, S. A. P. As especializações: histórico e projeções. In: NEGRI, B.; FARIA, R. \& VIANA, A. L. D. (Orgs.). Recursos Humanos em Saúde: política, desenvolvimento e mercado de trabalho. Campinas: Editora Unicamp, 2002.

BRASIL. Ministério do Trabalho e Emprego. Relação Anual de Informações Sociais: competência 2010. Brasília: MTE, SPPE, DES, CGET, 2011. CD-ROM.

BRASIL. Lei 12.871, 22 de out. 2013. Institui o Programa Mais Médicos, altera as Leis n. 8.745, de 9 de dezembro de 1993, e n. 6.932, de 7 de julho de 1981, e dá outras providências. Diário Oficial da União, Brasília, 2013.

CARVALHO, J. A. M. \& GARCIA, R. A. O envelhecimento da população brasileira: um enfoque demográfico. Cadernos de Saúde Pública, 19(3): 725-733, 2003.

CENTRO DE DESENVOLVIMENTO E PLANEJAMENTO REGIONAL (CEDEPLAR). Projeção Populacional das Unidades da Federação, Brasil, por Sexo e Grupos Quinquenais de Idades, 1990-2020. Belo Horizonte: Cedeplar, Universidade Federal de Minas Gerais, 1999. (Mimeo.)

CENTRO DE DESENVOLVIMENTO E PLANEJAMENTO REGIONAL (CEDEPLAR). Estimativas de população: revisões preliminares incorporando informação do Censo Demográfico de 2010. Relatório de pesquisa. Belo Horizonte: Cedeplar, 2012.

CENTRO LATINOAMERICANO DE DEMOGRAFÍA (CELADE). Métodos para Proyecciones Demográficas. Santiago: Celade, 1984.

COALE, A. \& DEMENY, P. Regional Model Life Tables and Stable Populations. 2. ed. New York: Academic Press, 1983.

CONSELHO FEDERAL DE ENFERMAGEM (COFEN). Análise de Dados dos Profissionais de Enfermagem Existentes nos Conselhos Regionais. Brasília: COFEN, 2011. Disponível em: <http://www.cofen.gov.br/wp-content/ uploads/2012/03/pesquisaprofissionais.pdf>. Acesso em: 22 maio 2017.

CONSELHO FEDERAL DE ENFERMAGEM (COFEN). Enfermagem em Números. Brasília: COFEN, 2013. Disponível em: <http://www.cofen.gov.br/enfermagem-em-numeros>. Acesso em: jun. 2013.

CONSELHO FEDERAL DE MEDICINA (CFM). Portal Médico. Estatística. Disponível em: < http://portal.cfm.org. br/index.php?option=com_estatistica $>$. Acesso em: jun. 2013.

CONSELHO FEDERAL DE ODONTOLOGIA (CFO). Dados Estatísticos. Disponível em: < http://cfo.org.br/ servicos-e-consultas/Dados-estatisticos>. Acesso em: jun. 2013. 
DAL POZ, M. R.; PIERANTONI, C. R. \& GIRARDI, S. Formação, mercado de trabalho e regulação da força de trabalho em saúde no Brasil. In: GADELHA, P.; CARVALHO, J. N. \& PEREIRA, T. R. A Saúde no Brasil em 2030: diretrizes para a prospeç̧ão estratégica do sistema de saúde brasileiro. Rio de Janeiro: Fiocruz, Ipea, Ministério da Saúde, Secretaria de Assuntos Estratégicos da Presidência da República, 2013.

DEPARTAMENTO DE PLANEJAMENTO E REGULAÇÃO DA PROVISÃO DE PROFISSIONAIS DE SAÚDE (DEPREPS). Cadastro do Programa Mais Médicos. Brasília: DEPREPS/SGTES/MS, 2016.

GIRARDI, S. N. et. al. Avaliação nacional da demanda de médicos especialistas percebida pelos gestores de saúde. Relatório de Pesquisa. Belo Horizonte: Estação de Pesquisa de Sinais de Mercado, EPSM/NESCON/FM/ UFMG, 2009. Disponível em: < http://epsm.nescon.medicina.ufmg.br/epsm/>. Acesso em: 01 jul. 2014.

GIRARDI, S. et al. O trabalho precário em saúde: tendências e perspectivas na estratégia da saúde da família. Divulgação em Saúde Para Debate, 45: 11-23, 2010.

GIRARDI, S. N. et al. Monitoramento da demanda por especialidades e residências médicas no Brasil. Relatório de pesquisa. Belo Horizonte: Estação de Pesquisa de Sinais de Mercado, EPSM/NESCON/FM/UFMG, 2012. Disponível em: < http://epsm.nescon.medicina.ufmg.br/epsm/> . Acesso em: 01 jul. 2014.

GOIC, A. Disponibilidad de médicos en Chile y su proyección a mediano plazo. Revista Médica de Chile, 122: 141-153, 1994.

GOIC, A. Disponibilidad de médicos en Chile y su proyección a mediano plazo: cinco años después. Revista Médica de Chile, 127: 1.183-1.188, 1999.

INSTITUTO BRASILEIRO DE GEOGRAFIA E ESTATÍSTICA (IBGE). Microdados do Censo Demográfico: amostra de uso público. Rio de Janeiro: IBGE, 2002. CD-ROM.

INSTITUTO BRASILEIRO DE GEOGRAFIA E ESTATÍSTICA (IBGE). Brasil: tábua completa de mortalidade, 2009. Disponível em: <www.ibge.gov.br/home/estatistica/populacao/tabuadevida/2009/defaulttab.shtm>. Acesso em: 01 jul. 2014.

INSTITUTO BRASILEIRO DE GEOGRAFIA E ESTATÍSTICA (IBGE). Microdados da Amostra do Censo Demográfico 2010. Rio de Janeiro: IBGE, 2012. Disponível em: <http://ftp.ibge.gov.br/Censos/Censo_Demografico_2010/ Resultados_Gerais_da_AmosAmo/Microdados/>. Acesso em: 27 abr. 2012.

INSTITUTO NACIONAL DE ESTUDOS E PESQUISAS EDUCACIONAIS ANÍSIO TEIXEIRA (INEP). Dados Estatísticos dos Cursos de Graduação Presenciais, segundo as Instituições de Ensino e o Curso: Censo de 1991 a 2012. Brasília: Inep, 2013.

MEDINA, E. Necessidades de médicos em Chile. Revista Médica de Chile, 116: 389-394, 1988.

PEREIRA, R. H. M.; NASCIMENTO, P. M. \& ARAÚJO, C. T. Projeções de mão de obra qualificada no Brasil: cenários para a disponibilidade de engenheiros até 2020. Revista Brasileira de Estudos de População, 30(2): 519-548, 2013.

RODRIGUES, F. G. Médicos em Minas Gerais: projeções para o período 2010-2020, 2008. Dissertação de Mestrado, Belo Horizonte: Universidade Federal de Minas Gerais.

SHRYOCK, H. S.; SIEGEL, J. S. \& STOCKWELL, E. G. The Methods and Materials of Demography. New York: Academic Press, 1976.

ZAEYEN, A. et al. Economia política da saúde: uma perspectiva quantitativa. Texto para Discussão $n^{\circ} 370$, Rio de Janeiro: Instituto de Pesquisa Econômica Aplicada, 1995. 


\section{APÊNDICE}

Tabela 1 - Estimativas de esperança de vida ao nascer para a população total e para os profissionais médicos, enfermeiros e cirurgiões-dentistas. Brasil - 2010

\begin{tabular}{|l|c|c|}
\hline & Homens & Mulheres \\
\hline 1. População Total do Brasil (*) & 69.4 & 77.0 \\
\hline 2. Médicos e Cirurgiões-dentistas (**) & 73.1 & 81,3 \\
\hline 3. Enfermeiros (**) & 69.4 & 77.0 \\
\hline Diferença entre (1) e (2) & 3.7 & 4.3 \\
\hline Diferença entre (1) e (3) & 0.0 & 0.0 \\
\hline
\end{tabular}

* Tábua de Mortalidade de 2009 do IBGE

** Estimativa realizada segundo o sistema de tábuas-modelo de Coale e Demeny (1983), com base nos dados do MTE (Brasil, 2011)

Tabela 2 - Evolução do número de cursos de medicina, vagas, inscritos no vestibular, ingressos, matriculados e egressos. Brasil - 1991-2012

\begin{tabular}{|c|c|c|c|c|c|c|c|}
\hline Ano & Cursos & Vagas & Inscritos vestibular & Ingressos & Matriculados & Egressos & Acumulado 10 anos \\
\hline 1991 & 80 & 7.786 & 170.151 & 7.667 & 46.881 & 7.315 & - \\
\hline 1992 & 80 & 7.864 & 174.128 & 7.875 & 47.753 & 7.074 & - \\
\hline 1993 & 80 & 7.800 & 198.657 & 7.683 & 47.386 & 7.228 & - \\
\hline 1994 & 81 & 7.979 & 201.218 & 7.820 & 47.919 & 7.622 & - \\
\hline 1995 & 85 & 8.247 & 241.503 & 7.888 & 47.934 & 7.194 & - \\
\hline 1996 & 86 & 7.946 & 250.944 & 7.845 & 48.667 & 7.347 & - \\
\hline 1997 & 88 & 9.001 & 261.620 & 8.764 & 48.601 & 7.705 & - \\
\hline 1999 & 92 & 9.202 & 263.384 & 9.566 & 50.879 & 7.616 & - \\
\hline 2000 & 100 & 9.469 & 288.571 & 9.500 & 52.304 & 7.758 & - \\
\hline 2001 & 106 & 10.089 & 282.065 & 10.313 & 57.930 & 8.363 & 76.152 \\
\hline 2002 & 115 & 11.243 & 326.482 & 10.830 & 59.755 & 8.498 & 77.335 \\
\hline 2003 & 126 & 12.281 & 321.532 & 11.898 & 60.912 & 9.113 & 79.220 \\
\hline 2004 & 136 & 12.824 & 334.431 & 12.894 & 64.965 & 9.339 & 80.937 \\
\hline 2006 & 149 & 14.661 & 313.683 & 14.283 & 68.834 & 10.004 & 83.747 \\
\hline 2007 & 160 & 15.278 & 303.076 & 15.424 & 74.034 & 10.381 & 86.781 \\
\hline 2008 & 177 & 16.241 & 364.108 & 16.267 & 79.246 & 10.133 & 89.209 \\
\hline 2009 & 185 & 16.876 & 390.774 & 17.339 & 97.994 & 11.881 & 96.541 \\
\hline 2010 & 181 & 16.468 & 542.007 & 18.473 & 103.312 & 12.982 & 101.519 \\
\hline 2011 & 188 & 16.852 & 695.964 & 18.253 & 108.142 & 14.634 & 107.790 \\
\hline 2012 & 206 & 17.931 & 850.674 & 20.203 & 111.530 & 16.354 & 132.507 \\
\hline
\end{tabular}

Fonte: elaboração própria, com base nos dados do Inep (2013). 
Tabela 3 - Evolução do número de cursos de enfermagem, vagas, inscritos no vestibular, ingressos, matriculados e egressos. Brasil - 1991-2012

\begin{tabular}{|c|c|c|c|c|c|c|c|}
\hline Ano & Cursos & Vagas & Inscritos vestibular & Ingressos & Matriculados & Egressos & Acumulado 10 anos \\
\hline 1991 & 108 & 7.460 & 28.995 & 6.889 & 22.237 & 3.434 & - \\
\hline 1992 & 110 & 7.311 & 27.517 & 6.588 & 22.873 & 3.340 & - \\
\hline 1993 & 107 & 7.334 & 32.789 & 6.769 & 24.470 & 3.795 & - \\
\hline 1994 & 108 & 8.252 & 35.722 & 7.759 & 26.040 & 4.373 & - \\
\hline 1995 & 108 & 8.068 & 43.800 & 7.806 & 27.477 & 4.733 & - \\
\hline 1996 & 111 & 8.283 & 43.990 & 8.059 & 29.414 & 5.065 & - \\
\hline 1997 & 123 & 9.905 & 53.287 & 10.238 & 31.873 & 5.411 & - \\
\hline 1998 & 140 & 11.376 & 59.728 & 11.215 & 33.543 & 5.447 & - \\
\hline 1999 & 153 & 13.781 & 76.951 & 13.789 & 37.179 & 5.522 & - \\
\hline 2000 & 183 & 20.417 & 102.974 & 17.996 & 45.342 & 6.355 & 47.475 \\
\hline 2001 & 215 & 24.646 & 122.337 & 23.723 & 53.179 & 7.139 & 51.180 \\
\hline 2002 & 285 & 37.061 & 186.823 & 34.475 & 71.475 & 9.102 & 56.942 \\
\hline 2004 & 332 & 47.347 & 201.621 & 45.558 & 92.134 & 11.252 & 64.399 \\
\hline 2005 & 474 & 70.400 & 230.680 & 59.253 & 120.851 & 13.965 & 73.991 \\
\hline 2006 & 564 & 95.367 & 223.497 & 67.508 & 153.359 & 19.968 & 89.226 \\
\hline 2007 & 636 & 108.629 & 242.386 & 73.036 & 186.955 & 25.755 & 109.916 \\
\hline 2008 & 690 & 117.340 & 234.738 & 79.263 & 224.742 & 39.276 & 170.950 \\
\hline 2009 & 765 & 119.966 & 259.042 & 74.699 & 235.281 & 40.853 & 206.281 \\
\hline 2010 & 805 & 133.243 & 258.337 & 71.244 & 245.462 & 42.940 & 242.866 \\
\hline 2011 & 847 & 121.051 & 298.188 & 70.903 & 246.876 & 47.830 & 283.557 \\
\hline 2012 & 871 & 120.180 & 341.761 & 76.891 & 236.713 & 47.050 & 321.505 \\
\hline & & & & & \\
\hline
\end{tabular}

Fonte: elaboração própria, com base nos dados do Inep (2013). 
Tabela 4 - Evolução do número de cursos de odontologia, vagas, inscritos no vestibular, ingressos, matriculados e egressos. Brasil - 1991-2012

\begin{tabular}{|l|l|l|l|l|l|l|l|}
\hline Ano & Cursos & Vagas & Inscritos vestibular & Ingressos & Matriculados & Egressos & Acumulado 10 anos \\
\hline 1991 & 83 & 7.315 & 118.162 & 7.230 & 30.702 & 6.089 & - \\
\hline 1992 & 85 & 7.691 & 116.191 & 7.758 & 31.950 & 6.203 & - \\
\hline 1993 & 86 & 7.996 & 107.738 & 8.006 & 33.388 & 6.355 & - \\
\hline 1994 & 89 & 8.253 & 116.476 & 8.126 & 35.101 & 6.773 & - \\
\hline 1995 & 91 & 8.521 & 136.927 & 8.461 & 35.999 & 6.964 & - \\
\hline 1996 & 93 & 8.476 & 141.556 & 8.396 & 37.303 & 7.050 & - \\
\hline 1997 & 101 & 9.643 & 132.918 & 10.488 & 38.631 & 7.613 & - \\
\hline 1998 & 117 & 11.267 & 116.243 & 11.777 & 41.093 & 7.710 & - \\
\hline 2000 & 131 & 13.304 & 108.820 & 12.908 & 43.815 & 8.011 & - \\
\hline 2001 & 153 & 14.051 & 97.533 & 13.285 & 46.324 & 7.742 & 70.510 \\
\hline 2002 & 159 & 15.701 & 84.617 & 13.961 & 47.753 & 9.281 & 73.186 \\
\hline 2003 & 171 & 16.333 & 71.455 & 13.195 & 46.915 & 9.848 & 79.757 \\
\hline 2004 & 174 & 15.733 & 69.517 & 13.270 & 46.039 & 9.056 & 82.040 \\
\hline 2005 & 179 & 16.301 & 66.919 & 13.170 & 46.731 & 8.919 & 83.995 \\
\hline 2007 & 185 & 16.841 & 64.007 & 13.550 & 46.693 & 8.533 & 85.478 \\
\hline 2008 & 193 & 18.266 & 63.621 & 14.198 & 46.723 & 8.366 & 86.231 \\
\hline 2009 & 196 & 19.257 & 67.258 & 15.523 & 48.752 & 8.754 & 87.275 \\
\hline 2010 & 201 & 19.069 & 81.893 & 16.338 & 57.603 & 8.930 & 88.962 \\
\hline 2011 & 209 & 20.861 & 102.963 & 18.753 & 63.590 & 9.637 & 89.834 \\
\hline 2012 & 215 & 20.589 & 134.670 & 23.057 & 70.293 & 10.269 & 90.822 \\
\hline
\end{tabular}

Fonte: elaboração própria, com base nos dados do Inep (2013). 